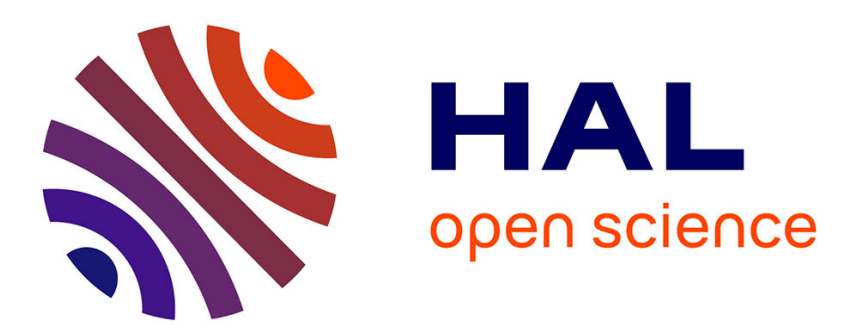

\title{
Effect of dislocation channeling on void growth to coalescence in FCC crystals
}

P.O. Barrioz, J. Hure, B. Tanguy

\section{To cite this version:}

P.O. Barrioz, J. Hure, B. Tanguy. Effect of dislocation channeling on void growth to coalescence in FCC crystals. Materials Science and Engineering A- Structural Materials Properties Microstructure and Processing, 2019, A749, pp.255-270. 10.1016/j.msea.2019.01.115 . cea-02339873

\section{HAL Id: cea-02339873 https://hal-cea.archives-ouvertes.fr/cea-02339873}

Submitted on 5 Nov 2019

HAL is a multi-disciplinary open access archive for the deposit and dissemination of scientific research documents, whether they are published or not. The documents may come from teaching and research institutions in France or abroad, or from public or private research centers.
L'archive ouverte pluridisciplinaire HAL, est destinée au dépôt et à la diffusion de documents scientifiques de niveau recherche, publiés ou non, émanant des établissements d'enseignement et de recherche français ou étrangers, des laboratoires publics ou privés. 


\title{
Effect of dislocation channeling on void growth to coalescence in FCC crystals
}

\author{
P.O. Barrioz, J. Hure*, B. Tanguy \\ ${ }^{a}$ CEA Saclay, Université Paris-Saclay, DEN, Service d'Études des Matériaux Irradiés, 91191 Gif-sur-Yvette, France
}

\begin{abstract}
The effect of dislocation channeling - a heterogeneous deformation mode at the grain scale observed in irradiated, quenched or heavily cold-worked materials - on void growth to coalescence in Face-Centered-Cubic (FCC) crystals is investigated experimentally. Solution Annealed 304L austenitic stainless steel is used as a model FCC material, in a reference state or irradiated with protons in order to trigger dislocation channeling deformation mode. Micrometric cylindrical voids drilled using Focused Ion Beam (FIB) technique at the grain scale in thin tensile samples subjected to uniaxial stress loading conditions allows a detailed description of void growth and coalescence. Compared to the reference state where plasticity appears homogeneous at the void scale, dislocation channels strongly interact with voids at the irradiated state, especially at low applied strain where characteristic localization patterns are observed and described. As applied strain increases, deformation becomes more and more homogeneous at the void scale through gradual activation of secondary channels. Numerical simulations based on FCC crystal plasticity constitutive equations are performed and compared to experiments. The main experimental features are recovered by the numerical simulations, but discrepancies remain for both reference and irradiated states. Ductile fracture modeling in materials exhibiting dislocation channeling is finally discussed based on these experimental and numerical results.
\end{abstract}

Keywords: Ductile fracture, Void growth, Coalescence, Dislocation channeling, Irradiation

\section{Introduction}

Ductile fracture through void growth to coalescence is $\mathrm{a}_{30}$ common failure mode of metal alloys [1] which involves three different stages known as void nucleation, growth and coales5 cence [2, 3]. Inclusions or second-phase particles debonding or cracking [4] lead to voids that grow under diffuse plastic flow [5. 6] until coalescence occurs through localized plastic flow between adjacent voids [7, 8]. Early models [6] have emphasized the major roles played by porosity - void volume fraction

10 - and stress triaxiality - ratio of hydrostatic stress over deviatoric stress - on ductile fracture through void growth to coalescence, but also the effect of the mechanical behavior of the matrix material surrounding the voids through the hardening modulus [5]. The critical influence of matrix material behav15 ior has been subsequently detailed mainly through porous unitcells simulations, where both plastic anisotropy (i.e. through Hill's yield criterion) (see [9, 10, 11] and references therein) and strain-hardening effects [12, 13] were confirmed. Specific directions of the porous material appear harder or softer due 20 to plastic anisotropy, while void growth in materials exhibiting strong strain-hardening may be significantly diminished, as shown also experimentally in [14] and [15]. Early examinations of fracture surfaces characterized by dimples or recent Xray tomography visualization [16] show that, for many metal alloys, voids involved in ductile fracture have often a size well below the grain size, i.e., voids are in single crystals. In that case, the existence of well-defined sets of slip systems may ${ }_{55}$

${ }^{*}$ Corresponding author lead to a very strong plastic anisotropy that has been shown to influence void growth. Analytical [17] and experimental results [18, 19] showed the interactions between crystallographic orientations and void shapes as well as lattice rotations around voids. Full three-dimensional porous unit-cells simulations using crystal plasticity constitutive equations for the matrix material [20, 21, 22, 23] emphasized the influence of crystal orientation and void arrangement on void growth and coalescence, especially for low stress triaxialities. All these experimental and numerical results serve as a basis to the development of homogenized models for porous materials incorporating the effects of porosity, stress triaxiality, matrix anisotropy and hardening ([24, 25] for recent reviews) following early works of Gurson [26] and Thomason [27]. The most advanced contributions include the combined effects of void shapes and crystal plasticity for voids in single crystals [28, 29, 30].

Homogenized models for porous materials described hereabove consider that the matrix material around voids deforms rather homogeneously at the void scale. Such assumption comes from the choice of matrix material constitutive equations that do not exhibit softening, which is a necessary condition for strain localization to happen [31]. However, lower scale simulations such as Discrete Dislocations Dynamics (DDD) clearly indicate that heterogeneous dislocations structures do appear at void scale [32, 33, 34]. Finite element porous unit-cell simulations using softening matrix material [35] also show heterogeneous deformation through localization bands and their interactions with void growth. Materials exhibiting highly heterogeneous deformation mode at the grain scale through the appearance of localization bands are in fact not so uncommon, 
such as irradiated or quenched materials [36, 37]. Such phenomenon, referred to as dislocation channeling, is particularly observed and studied in irradiated metal alloys. Irradiation with ${ }_{100}$ high-energy particles, e.g., encountered in nuclear power plants, leads to the creation of crystalline defects such as dislocations, dislocation loops, nano-voids and precipitates in metallic materials [38, 39] through ballistic interactions between incident particles and atoms. In addition to drastic evolution of macro-105 scopic mechanical properties [40, 41, 42], the presence of these nano-scale defects can induce a change of deformation mechanisms at the grain scale where plasticity is observed to be confined into narrow channels surrounded by undeformed material

70 [43, 44]. From a metallurgical point of view, dislocation chan- -110 neling is explained by the removal of immobile irradiation defects by a leading dislocation, creating a clear path (free of defects) where following dislocations can easily glide [45, 46, 47]. From a mechanical point of view, the potential removal of irra-

75 diation defects corresponds to a softening mechanism that can ${ }_{115}$ trigger strain localization. An example of the manifestation of dislocation channeling is given in Fig. 1 1 , where widely spaced slip traces can be observed at the surface of an irradiated material under mechanical loading. Dislocation channeling deforso mation mode has consequences on the macroscopic mechanical properties of irradiated materials, such as limited hardening that favors macroscopic plastic instability [46] and a potential detrimental role in intergranular stress-corrosion cracking due to high stresses arising at the intersection between channels and 85 grain boundaries [48]. Dislocation channeling is not limited to irradiated materials, but has also been observed in quenched [49, 50] or predeformed [51] materials. The mechanism is sim- ${ }_{125}$ ilar to the case of irradiated materials, where defects that can be removed are created due to quenching or prestraining.

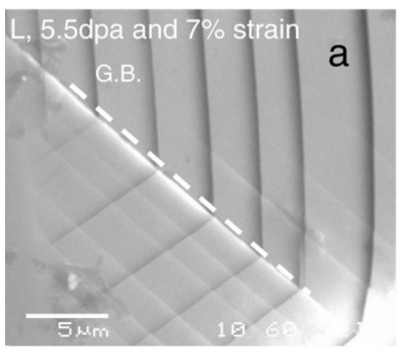

(a)

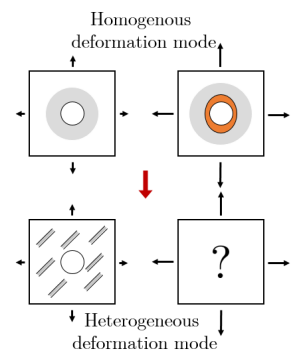

(b)
Figure 1: (a) Slip traces observed at the surface of a sample of irradiated austenitic stainless steel subjected to uniaxial stress loading conditions (taken from [52]), resulting from dislocation channeling deformation mode. (b) Sketch of the potential influence of dislocation channeling on void growth to coalescence mechanism

Recent experimental observations [53, 54, 55], numerical simulations [56, 57, 58] and analytical models [59] lead to a better understanding of channels initiation mechanisms, widths and spacings. However, the potential influence of dislocation channeling on micron-scale void growth to coalescence has not 95 been studied (Fig. 113), although ductile fracture is the dominant fracture mode of materials exhibiting dislocation channeling (e.g. irradiated austenitic stainless steels [60]). Therefore, ${ }^{140}$ the main objective of this study is to investigate experimentally the influence of dislocation channeling on micron-scale void growth to coalescence fracture mechanism. In addition, numerical simulations based on crystal plasticity constitutive equations are performed and compared to experimental results. In order to amplify the potential effects, void deformation under low applied stress triaxiality (where crystal anisotropy effects are known to be more significant) in highly irradiated material (where severe dislocation channeling is expected) are used in the following and compared to a reference (unirradiated) case where homogeneous deformation mode occurs.

The paper is organized as follows. In Section 2, the material and methods used are described, with an emphasis on the experimental setup allowing assessing void growth to coalescence in crystals and on obtaining a material exhibiting dislocation channeling deformation mode through irradiation. Section 3 describes the experimental results, comparing the effect of homogeneous $v s$. heterogeneous plasticity on void deformation as a function of applied plastic strain. Experimental results are discussed with respect to ductile fracture modeling in materials exhibiting dislocation channeling in Section 4, as well as compared to numerical results.

\section{Material and Methods}

In this section, the material and the methodology used in this study to assess experimentally the effect of dislocation channeling on void growth to coalescence in FCC crystals is detailed. In addition, the numerical method and constitutive equations used to model FCC single crystals are described.

\subsection{Material}

A commercial austenitic stainless steel of type 304L has been selected for this study. 304L has a Face-Centered-Cubic (FCC) crystallographic structure, and thus can serve as a model 30 alloy to describe other FCC materials where dislocation channeling is observed. Moreover, austenitic stainless steels have been thoroughly characterized with respect to the evolution of the mechanical properties [61] as well as deformation mechanisms [62, 44] with irradiation, and exhibit dislocation channel35 ing after irradiation when tested at high temperature $\left(300^{\circ} \mathrm{C}\right)$.

\begin{tabular}{lllllllll}
\hline $\mathrm{Pb}$ & $\mathrm{W}$ & $\mathrm{Zr}$ & $\mathrm{S}$ & $\mathrm{P}$ & $\mathrm{C}$ & $\mathrm{Mg}$ & $\mathrm{Co}$ & $\mathrm{Si}$ \\
\hline $8 \mathrm{ppm}$ & 0,035 & $12 \mathrm{ppm}$ & 0,002 & 0,010 & 0,012 & 0.003 & $<0,05$ & 0.450 \\
\hline \hline $\mathrm{Cu}$ & $\mathrm{V}$ & $\mathrm{Mo}$ & $\mathrm{Mn}$ & $\mathrm{Ti}$ & $\mathrm{Ni}$ & $\mathrm{Cr}$ & $\mathrm{Fe}$ & \\
\hline 0,240 & 0,015 & 0,020 & 1,650 & $<0,05$ & 8,55 & 18,75 & $\mathrm{Bal}$ & \\
\hline
\end{tabular}

Table 1: Chemical composition (in weight \%) of 304L austenitic stainless steel

304L is a material used for most parts of Light Water Reactors (LWR) internal structures [42], so that results obtained in this study will be relevant regarding industrial issues. The chemical composition of the material is given in Tab. 1 


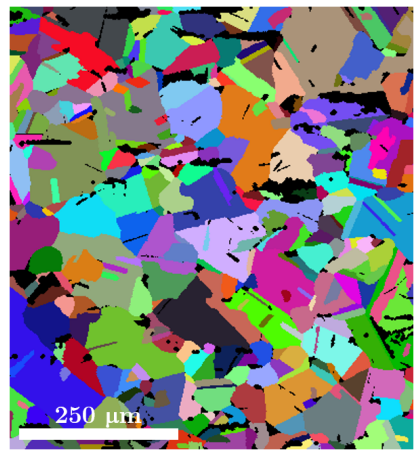

(a)

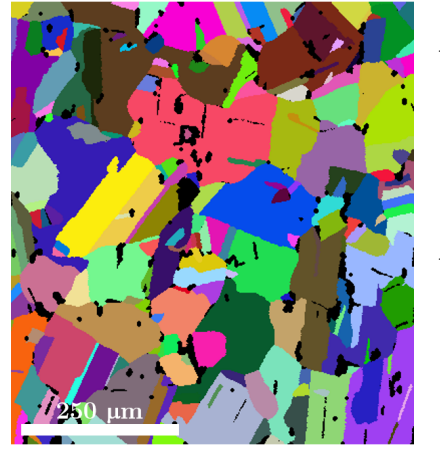

(b)
Figure 2: Electron Back-Scattered Diffraction (EBSD) analysis of the material, (a) in the as-received state and (b) after additional heat-treatment (4 hours at $1100^{\circ} \mathrm{C}$ followed by water quenching). Colors correspond to different crystallographic orientations. Heat treatment allows to make grains bigger and to reduce the number of small grains

The material was supplied in a solution annealed condition (Heat treatment of 30 minutes at $1100^{\circ} \mathrm{C}$ followed by water quenching). The methodology described in Section. 2.2 requiring large grain size, an additional heat treatment of 4 hours at C followed by water quenching was performed on plates (90x100x3mm) to obtain larger grains. Typical crystallographic structures obtained by Electron Back-Scattered Diffraction (EBSD) on the as-received material and after the additional heat treatment are given Fig. 2. The evolution of grain diameter distribution after the additional heat treatment shows a slight mean increase of $8 \mu \mathrm{m}$, but large grains in the as-received condition have grown significantly (up to $200 \mu$ m diameter). Hereafter, the (reference) material refers to the one with the additional heat treatment. The Vickers hardness was measured to be $193 \pm 10 \mathrm{HV}_{0.02}$ conventional Vickers micro-hardness machine with $20 \mathrm{~g}$ applied load and 10 seconds hold time. Tensile specimens of gage length $8 \mathrm{~mm}$, width $2 \mathrm{~mm}$ and thickness $2 \mathrm{~mm}$ were machined through electrical discharge machining. Tensile tests have been performed at $300^{\circ} \mathrm{C}$ on an universal testing machine, and stress-strain curve is given on Fig. 3 .

Solution-Annealed 304 austenitic stainless steel is known to deform rather homogeneously at the grain scale through dislocation glide in high temperature testing $\left(300^{\circ} \mathrm{C}\right)$ [44], and will thus serve as a reference state to assess the effect of dislocation coid growth. In order to get a material that has $\mathrm{a}^{200}$ dislocation channeling deformation mechanism, part of the tensile samples from the reference material were irradiated with high energy protons. An irradiation energy of $2 \mathrm{MeV}$ was selected in order to have a significant irradiated thickness, while the fluence $\left(\mathrm{H}^{+} . \mathrm{cm}^{-2}\right)$ and irradiation temperature were cho-205 sen in accordance to previous studies [52] so to have significant irradiation defects to trigger dislocation channeling. Prior to irradiation, tensile samples were mirror polished using standard polishing techniques up to $1 / 4 \mu \mathrm{m}$ diamond paste. $2 \mathrm{MeV}$ proton irradiation was performed at $350^{\circ} \mathrm{C} \pm 10^{\circ} \mathrm{C}$ on tensile $\mathrm{e}_{210}$ samples using Tandem accelerator at Michigan Ion Beam Laboratory, University of Michigan [63]. The integrated fluence is $5.5710^{19} \mathrm{H}^{+} . \mathrm{cm}^{-2}$ with a flux about $210^{14} \mathrm{H}^{+} \cdot \mathrm{cm}^{-2} \cdot \mathrm{s}^{-1}$.
Temperature was controlled by an infrared camera and using 4 thermocouple probes (Fig. 4a) welded on the tensile samples and calibrated prior to irradiation. As discussed in [64], these conditions lead to irradiation defects in quantitative agreement (number, size) with the ones observed for neutron irradiation at about $290^{\circ} \mathrm{C}$, so that the irradiated material obtained in this study is relevant for Light Water Reactors conditions. Irradiation levels are usually characterized with Displacements Per Atoms (noted dpa) value that attempts to compute the average value an atom from the material has been displaced from its lattice position during the irradiation. Such value is particularly relevant when comparing irradiations with different particles (neutrons, ions, electrons). SRIM-2013 software [65] was used to compute dpa, using Kinchin-Pease (KP) model [66] and a displacement energy of $40 \mathrm{eV}$ for $\mathrm{Fe}, \mathrm{Cr}$ and $\mathrm{Ni}$ [67]. The damage profile is given in Fig. $4 \mathrm{p}$, showing an irradiated layer of about $18 \mu \mathrm{m}$ depth. As shown in [52], for these irradiation levels, dislocation channeling is expected under mechanical loading at $300^{\circ} \mathrm{C}$. The irradiated microstructure constituted mainly of Frank dislocation loops has been fully characterized, and results are detailed in Appendix A.

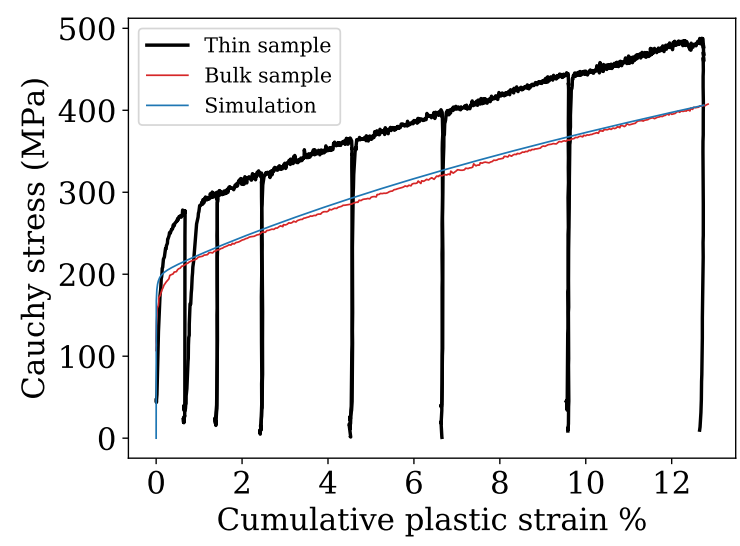

Figure 3: Tensile curves - Cauchy stress as a function of cumulated plastic strain - for the reference material (as-received with additional heat treatment). Experimental results on a thick tensile sample (Bulk sample) and thin tensile sample (Thin sample, see Section 3. Numerical result using a polycrystalline Voronoi aggregate and FCC crystal plasticity constitutive equations (Section 2.2.

\subsection{Methods}

\subsubsection{Experimental methodology}

The experimental methodology used to assess void growth and coalescence is derived from the one proposed by Weck \& Wilkinson [68] based on model cylindrical holes obtained through laser machining in thin tensile samples. Upon straining, monitoring voids shapes evolutions with Scanning Electron Microscope (SEM) as a function of applied strain allows to assess the physical mechanisms involved as well as to evaluate models, as still done recently in [69].

Substantial modifications of the original setup are required to assess void growth in single crystals exhibiting dislocation channeling deformation mode. Firstly, as described in Section 2.1, the maximal depth of the irradiated layer is about $20 \mu \mathrm{m}$ 


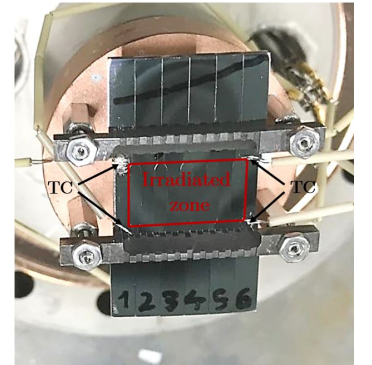

(a)

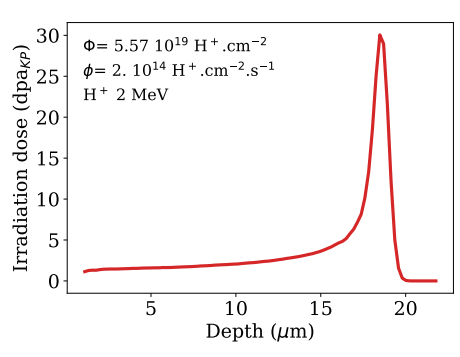

(b)
Figure 4: (a) Irradiation setup: Tensile samples are mounted on a copper stage cooled by liquid nitrogen to compensate heating due to high flux proton irradi-26 ation. Details about the irradiation setup can be found in [63] (b) Dose in dpa as a function of depth through the thickness of the 304L samples. Dpa level is computed using SRIM-2013 software [65], using Kinchin-Pease (KP) model, with a displacement energy of $40 \mathrm{eV}$.

- with an almost constant irradiation dose thickness of about

$15 \mu \mathrm{m}$ - so that tensile samples used should be thinned down to less than $20 \mu \mathrm{m}$ to get an almost homogeneous sample exhibiting dislocation channeling. This thickness also ensures to get a polycrystalline material with mostly one grain across the thickness - at least for large ones - due to the grain growth heat treatment applied (Section 2.1). Tensile samples are thinned down to less than $20 \mu \mathrm{m}$ by mechanical polishing: SiC grinding paper is used with grit of 320 up to $200 \mu$ m thickness, then 600 grit up to $100 \mu \mathrm{m}$ and 1200 grit until the final thickness. The thickness of the samples is regularly measured with a dial indicator to verify the good parallelism of the samples faces, and finally precisely measured in SEM.

Secondly, as irradiation was performed before drilling the cylindrical holes, laser machining technique has been replaced ${ }^{270}$ by another technique, as laser induces local heating that might remove close to the holes the irradiation defects needed to get dislocation channeling mechanism. Focused-Ion Beam (FIB) machining was selected as it does not involve any heating, and generates artefacts (additional irradiation defects) only in very ${ }^{275}$ limited regions ( $\lesssim 100 \mathrm{~nm}$ ). On one face of the sample, an electrochemical attack (using 60\% volume nitric acid at 65\%, 40\% volume water) is first performed to reveal grain boundaries and to select large grains. EBSD analysis is also performed all along the gauge surface to assess crystallographic orientations. Cylin-280 drical voids (either one or two) are then drilled using FIB in singrains throughout the thickness of the tensile samples. FIB milling leads to slightly conical through-thickness void shape that is minimized by performing drilling on both sides of the specimens. Void diameter, selected as the smallest allowing ${ }^{285}$ drilling completely through the thickness of the thin samples, the middle of the specimen than on the surface. For the reference material (resp. irradiated), voids mean diameter is $11.0 \mu \mathrm{m}$ (resp. $4 \mu \mathrm{m}$ ), with intervoid distance of $15 \mu \mathrm{m}$ (resp. $7.5 \mu \mathrm{m}$ ) when two adjacent voids are drilled.

In addition, in order to get full-field strain measurements through high resolution Digital Image Correlation (DIC), a speckle pattern is generated on the other face of the sample by the re- modeling of a deposited gold layer using the methodology developed in [70]. Surface is polished up to $1 / 4 \mu \mathrm{m}$ diamond paste and then polished during $10 \mathrm{~min}$ with a colloidal silica solution $(0.05 \mu \mathrm{m}, \mathrm{pH}=7)$. A $70 \mathrm{~nm}$ gold layer is deposited using a standard metallizer. Finally, the gold film is remodeled during $1 \mathrm{~h}$ at $300^{\circ} \mathrm{C}$ under water vapor leading to a speckle pattern with speckles size from 100 to $200 \mathrm{~nm}$ (see Inset Fig. 7p).

This methodology, described schematically in Fig. 5, allows to get thin tensile samples with model cylindrical holes in FCC crystals, for both reference material that have homogeneous deformation mode at the grain scale and irradiated material having dislocation channeling deformation mode. For the latter, as the material is expected to exhibit early macroscopic necking due to limited strain-hardening capability, notches have also been drilled using FIB at locations where voids have been drilled, in order to ensure that plasticity will take place in that area (Fig. 10p).

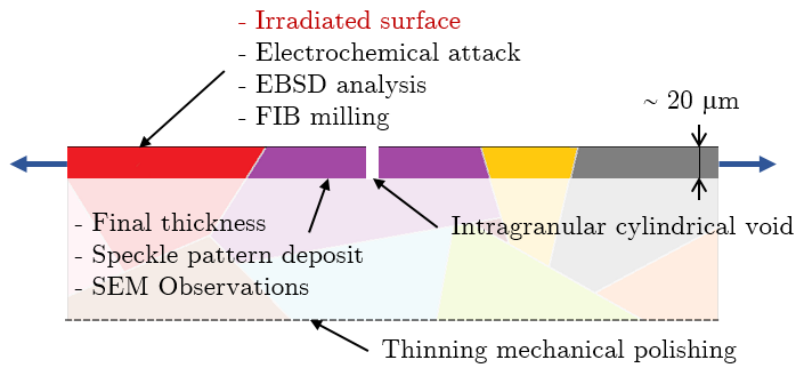

Figure 5: Overview of the different steps of samples preparation: mirror polishing, irradiation, thinning of bulk samples by mechanical polishing leading to fully irradiated $2 \mathrm{D}$ polycrystalline aggregate (with one grain along the thickness), FIB drilling of cylindrical holes in grains.

Tensile tests are performed on an in-situ SEM micro mechanical tensile machine equipped with a $200 \mathrm{~N}$ load cell at a mean strain rate of $10^{-4} \mathrm{~s}^{-1}$. A resistive heater in direct contact with the back of the specimen allows heating to a target temperature of $300^{\circ} \mathrm{C}$. Because of the extreme thickness of the samples, temperature is not measured during the tensile tests. Tests are performed previously to calibrate the temperature of the resistive heater to have a temperature of $300^{\circ} \mathrm{C}$ on the thin sample (measured with a thermocouple). The uncertainty on the temperature value is estimated to be $\pm 25^{\circ} \mathrm{C}$. Interrupted tensile tests are performed to monitor the evolution of voids shapes as a function of applied strain. For each (pair of) void in the reference material, SEM acquisitions are performed using back-scattered electrons mode signal with a resolution of $2048 \times 1536$ pixels. The magnification is $\times 2000$. The contrast is maximized while limiting the noise in order to facilitate the digital image correlation. For the irradiated material, acquisitions are performed using secondary electrons mode signal with a resolution of $3072 \times 2304$ pixels.

\subsubsection{Numerical methods}

Digital image correlation is performed using Yadics software [71] with the finite element method ( $8 \times 8$ subdivision pixel is used and $5 \times 5$ median filter). Results are plotted with a $2 \mathrm{D}$ equivalent strain defined as: $\varepsilon_{e q}=[2 / 3] \sqrt{\varepsilon_{x x}^{2}+\varepsilon_{y y}^{2}+2 \varepsilon_{x y}^{2}}$. 
Numerical simulations of the experiments are performed using crystal plasticity models and Fast Fourier Transform(FFT) based solver AMITEX_FFTP [72]. Details about these simulations can be found in Appendix B so that only the modeling of the mechanical behavior of the material and boundary conditions are described in this section. Simulations relie on crystal plasticity constitutive equations that are widely used in the literature to describe single crystals in structural calculations [73], accounting for the existence of slip systems that are activated once the resolved shear stress on a given slip system exceeds a critical value. In a viscoplastic version of crystal plasticity, the flow rule is:

$$
\dot{\gamma}^{\mathrm{s}}=\left\langle\frac{\left|\tau^{\mathrm{s}}\right|-\tau_{\mathrm{c}}^{\mathrm{s}}}{\mathrm{K}}\right\rangle_{+}^{\mathrm{n}} \operatorname{sign}\left(\tau^{\mathrm{s}}\right), \quad \text { with }\langle\bullet\rangle_{+}=\left\{\begin{array}{l}
\bullet \\
0 ; \bullet>0 \\
0 ; \bullet 00
\end{array}\right.
$$

where $\gamma^{s}$ and $\tau^{s}=\sigma: \mathbf{N}^{s}$ are the shear strain and resolved shear stress in slip system $s$, respectively, with $\mathbf{N}^{s}=m^{s} \otimes n^{s}$ the Schmid tensor characterizing a slip system of normal $n^{s}$ and direction $m^{s}$. Parameters $K$ and $n$ regulate the viscosity of the plastic flow, and are usually used only for numerical purposes close to the rate independent limit. $\tau_{c}^{s}$ corresponds to the critical resolved shear stress that evolves with shear strain, thus modeling strain-hardening. For the reference material, physicallybased hardening for austenitic stainless steels described in [74] is used. The critical resolved shear stress is written:

$$
\tau_{\mathrm{c}}^{\mathrm{s}}=\tau_{0}+\mu \sqrt{\sum_{u} a^{s u} r^{u}} \quad \dot{\mathrm{r}}^{\mathrm{s}}=\left(\frac{\sqrt{\sum_{s} b^{s u} r^{u}}}{\kappa}-\mathrm{G}_{\mathrm{c}} \mathrm{r}^{\mathrm{s}}\right)\left|\dot{\gamma}^{\mathrm{s}}\right|
$$

where $r^{s}$ is the normalized dislocation density in the slip sys-315 tem s and $a^{s u}$ is a $12 \times 12$ matrix with 6 independent parameters which characterize the long-range interactions between dislocations. The evolution of dislocations in slip systems is composed by a multiplicative and an annihilation terms. $b^{s u}$ is an interaction matrix with the same shape of $a^{s u} . \kappa$ is proportional $l_{320}$ to the number of obstacles crossed by a dislocation before being immobilized and $G_{c}$ depends on the annihilation mechanisms of dislocations. Parameters of the law are taken from [74], except three parameters $\left(\tau_{0}, \kappa\right.$ and $\left.G_{c}\right)$ that have been obtained through calibration of the tensile response of a $3 \mathrm{D}$ polycrystalline Voronoi aggregate against experimental tensile curve from a bulk sample - similarly to what have been done in ${ }^{325}$ [75] - leading to: $\left\{\tau_{0}=70 \mathrm{MPa}, \kappa=10, G_{c}=12\right\}$. The comparison between the experimental and numerical tensile curves is given in Fig. 3 .

For the material where dislocation channeling is expected, crystal plasticity constitutive equations have been proposed in the literature to describe the presence of removable irradiation ${ }^{330}$ defects [75, 76, 77], leading to locally softening behavior and to the appearance of localization bands. These models involve many additional state variables / parameters and are numerically heavy. Thus, a simple phenomenological softening law (Eq.3) is used. Slip systems are considered independent to each ${ }^{335}$ other as a first approximation. The second term of Eq. 3 aims at modeling softening induced by the removal of irradiation defects. At large strains, re-hardening is expected due to multiplication of dislocations, corresponding to the third term added in

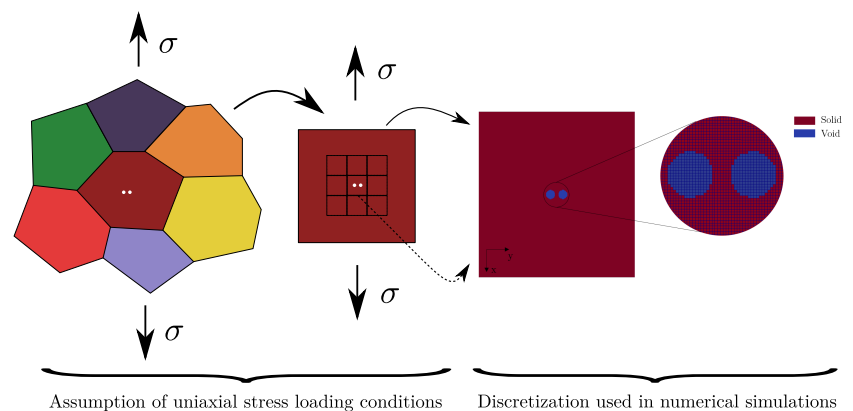

Figure 6: Assumption of uniaxial stress loading conditions at the grain scale used in the numerical simulations, by considering either static uniform boundary conditions or periodic boundary conditions (Appendix B)

Eq.3 In all simulations reported hereafter, the values of the parameters are set to $\left(\tau_{0}=100 \mathrm{MPa}, \Delta \tau_{1}=50 \mathrm{MPa}, \gamma_{0}=0.01\right)$, but have no influence on localization patterns reported in Section 4. The parameter $\Delta \tau_{2}$ is set equal to $\Delta \tau_{1}$ or zero to assess the effect of rehardening.

$$
\tau_{\mathrm{c}}^{\mathrm{s}}=\tau_{0}+\Delta \tau_{1} \exp -\left(\frac{\gamma^{\mathrm{s}}}{\gamma_{0}}\right)+\frac{\Delta \tau_{2}}{\gamma_{0}}\left|\gamma^{\mathrm{s}}-\gamma_{0}\right|
$$

In order to be able to perform numerical simulations only at the single grain scale where the voids are drilled, an assumption has to be made regarding the stress/strain state of a single grain inside a $2 \mathrm{D}$ polycrystalline aggregate subjected to uniaxial stress loading conditions. Low constraint along the thickness leads to assume that uniaxial stress conditions also applies at the grain scale. A unit cell containing (one or) two cylindrical voids is thus considered, as shown on Fig.6 Uniaxial stress state can be applied either considering static uniform boundary conditions either assuming periodic boundary conditions. Both conditions can be applied through FFT based simulations, as shown in Appendix B, where the latter is a standard loading condition while the former can be made adding free surfaces at the cell boundaries. The choice between these two boundary conditions is detailed and discussed in Section 4

\section{Experimental results}

\subsection{Homogeneous deformation mode}

Interrupted tensile test has been performed on the reference material tensile sample of thickness $\sim 15 \mu \mathrm{m}$, with seven strain increments, the last one corresponding to fracture of the sample. After each increment, applied load was kept constant during the acquisition of SEM images of the voids. The tensile curve obtained with the thin sample is given on Fig. 3. Compared to the tensile curve of the reference material obtained on a bulk sample, higher stress is measured for the thin sample, which was suspected to come from a hardened layer induced by the mechanical polishing. Transmission Electron Microscope (TEM) investigation (not shown here) revealed a higher dislocation density than a typical solution annealed state under the surface, at least to a depth of $7 \mu \mathrm{m}$ (which corresponds to the 


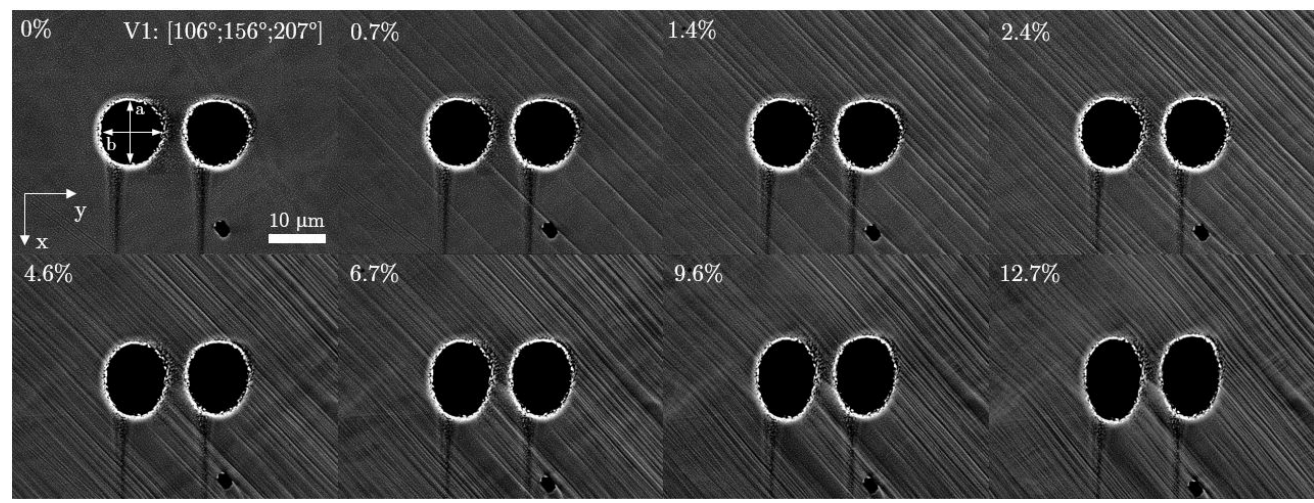

(a)

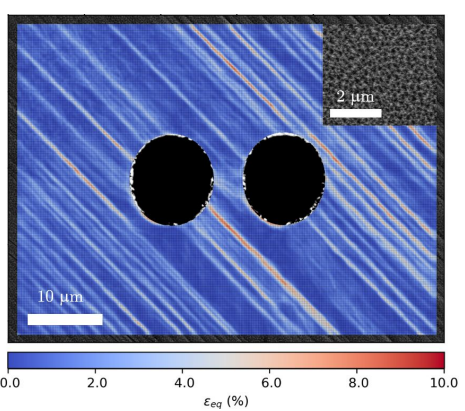

(b)

Figure 7: (a) Evolution of voids shapes as a function of macroscopic plastic strain inside a grain with crystallographic orientation $\left[106^{\circ}, 156^{\circ}, 207^{\circ}\right]($ Euler angles orientation with the Bunge convention (zx'z") obtained through EBSD on the other side of the sample (Fig. 5) . Tensile direction is along $x$ (b) Digital image correlation on voids V1 between the images taken at $1.4 \%$ and $2.3 \%$ macroscopic plastic strains. Inset: Initial speckle pattern

depth of the TEM sample). The average hardening (across the thickness) due to mechanical polishing corresponds to a prestrain of about 4\% (Fig. 3). However, such pre-strain is not ex-380 pected to influence void evolution as a function of applied strain as the macroscopic strain-hardening modulus - which is a key parameter [14] - is rather constant in that range of deformation.

Figure $7 \mathrm{k}$ shows the typical evolution of two voids under mechanical loading. Voids elongate along the tensile direction,385 and shrink along the perpendicular direction, as expected from such low stress triaxiality conditions [68]. Due to premature failure of the tensile sample (which is expected for such thin samples that are known to be sensitive to machining imperfections), no coalescence events have been observed. As deforma- 390 tion increases, lines can be seen on the images that correspond to steps on the tensile specimen surface. These steps are the traces of activated slip systems that have a slip direction with a non-zero component along the normal direction of the samples, thus leading to an extrusion which are well captured with SEM ${ }_{395}$ images sensitive to topology changes. On that particular case, only one slip system appears to be activated. As a slip system with slip direction perpendicular to the sample normal would not lead to steps - thus being invisible with SEM images - digital image correlation has been performed to assess the potential 400 activation of secondary slip systems. Fig. $7 \mathrm{p}$ shows a typical example of strain field obtained where no clear indication of activation of other slip systems can be found. Thus, a single slip state occurs, consistently with the uniaxial stress loading conditions associated with non-symmetric crystallographic ori-405 entation. Voids are found to have no clear influence on plasticity as slip bands have similar orientations far and close to the voids. Similar observations were also done in [78] on voids in an aluminum alloy where plastic slip traces appear to run across the voids.

Analysis of other void shapes evolutions on the same tensile sample but in different grains leads mainly to the same conclusions. In all cases, crystallographic orientations are, as in the first case, non-symmetric with respect to the loading direction. Fig. 8 shows the different sets of voids for a given ap- plied macroscopic strain, which are very similar qualitatively to what have been already discussed based on Fig. 7 for voids denoted V1, V2, V3 and V4. For voids V5 and V6, slip lines patterns suggest the presence of grain boundaries close to the voids which complicates the analysis. As almost uniaxial stress state is expected at the grain scale especially due to the presence of only one grain along the thickness (Fig. 5), the computation of the highest Schmid factor $\mathrm{S}$ (defined such as $\tau^{S}=S \sigma$ ) is expected to find the active slip system. This is confirmed on Fig. 8 where slip traces of the slip system with the highest Schmid factor match well with the slip traces observed for voids V1, V2, V4 and V5. This also confirms that, for these voids, there is only one grain along the thickness as EBSD measurements used to compute crystallographic orientations and thus Schmid factors - have been performed on the other side of the specimen (Fig. 5b. For voids V3 and V6, no agreement is observed, probably related to the presence of several grains along the thickness, so that the orientations reported on Fig. 8 may not describe the crystal throughout the thickness.

Quantitatively, the evolution of voids axis $a$ and $b$ (defined as the axis of an ellipse inscribed in the voids Fig. 77, averaged on the two voids) as a function of engineering plastic strain (denoted $F_{x x}-1=\Delta l / l_{0}$, with $l_{0}$ the initial gage lenth of the tensile sample, and $\Delta l$ the elongation) measured from the tensile curve are plotted on Fig. 9 Even though voids deformation appears qualitatively similar, as shown in Fig. 8, significant differences are observed due to crystallographic effects, which have been shown to be predominant for void shape evolution under low stress triaxialities conditions in numerical simulations [33, 79, 80, 81]. Differences of void elongation along the tensile direction up to $100 \%$ are found, e.g. between voids V1 and V2. Experimental results on voids evolutions in the reference material, that exhibits very homogeneous deformation mode, serve as a reference case to be compared to similar results described in the next section in presence of dislocation channeling.

\subsection{Dislocation channeling deformation mode}

As for the reference material exhibiting homogeneous deformation mode, interrupted tensile tests have been performed 


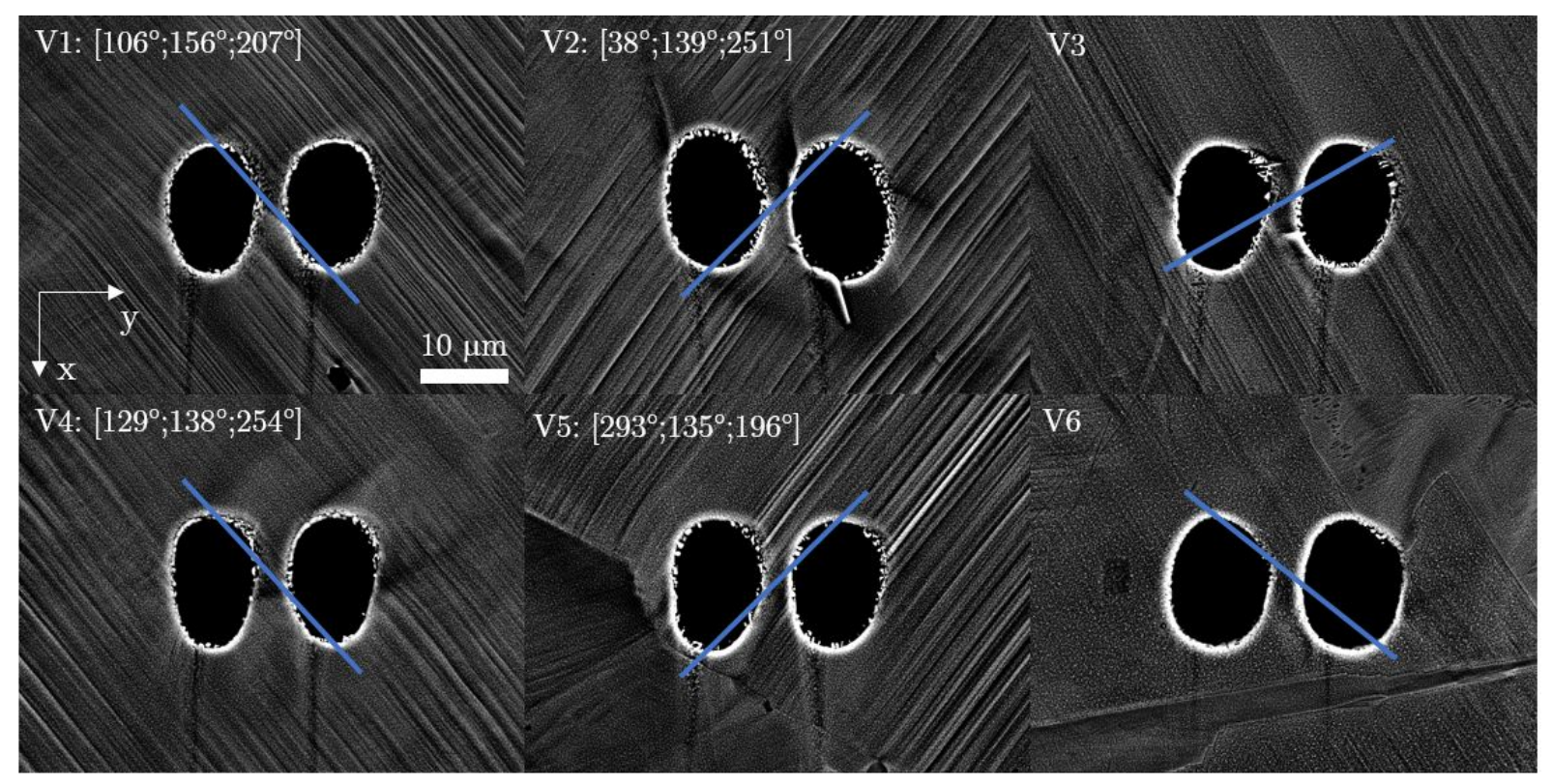

Figure 8: Comparison of the voids shapes for 6 different pairs of voids at $12.7 \%$ macroscopic plastic strain on the reference material sample. Tensile direction is along $x$. Euler angle orientations of the grains, given with the Bunge convention [zx'z"]), are obtained by EBSD analysis on the other side of the sample (Fig. 5]. Blue line is the intersection between the surface and the slip plane of the slip system having the highest Schmid factor calculated assuming uniaxial stress state and computed on the undeformed configuration.

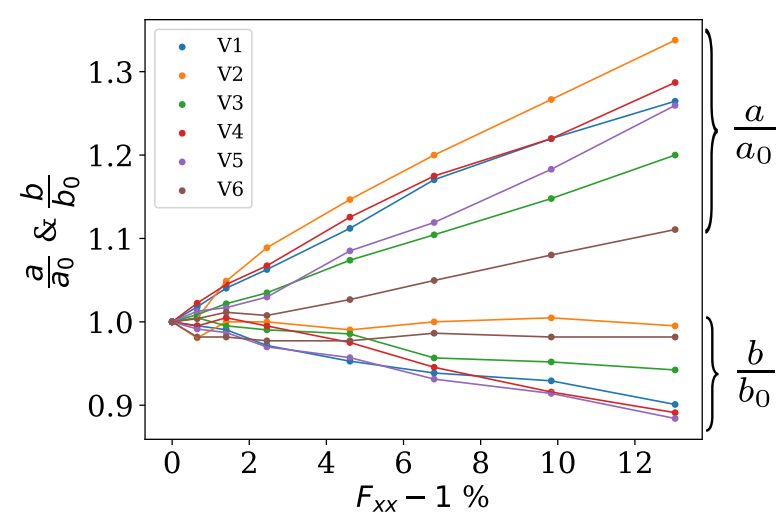

Figure 9: Evolution of voids axis $a$ and $b$ (defined as the axis of an ellipse inscribed in the voids, see Fig. 7) as a function of engineering plastic strain (denoted $F_{x x}-1=\Delta l / l_{0}$, with $l_{0}$ the initial gage lenth of the tensile sample, and $\Delta l$ the elongation) for the reference material

on the irradiated thin tensile samples - expected to have dislocation channeling deformation mode. The only difference is that notches have been drilled on the tensile samples (Fig. 10p) to macroscopically localize deformation in the region where voids ${ }^{450}$ have been drilled, as early necking of such material is expected. Average applied strain along the tensile direction applied to the voids can not be computed from the tensile curve, contrary to the reference material. Moreover, in case where deformation is not homogeneous, any measure of strain is dependent on the ${ }^{455}$ reference length on which it is computed. Thus average strain levels along the tensile direction (along the $x$ axis) are evaluated using displacements measured at the boundaries of the images taken of voids shapes and reference length equal to the images' height (Fig. 10a), for comparisons purposes to the reference material.

Figure 10 shows typical results at the early stages of voids deformations, corresponding to very low applied strain on the tensile sample. Highly localized deformation mode is observed with plasticity localized into few channels, leading to steps on the sample surface. Transmission Electron Microscopy (TEM) observations shown in Appendix $\mathrm{C}$ confirm that these channels correspond to regions where irradiation defects have been removed, thus to dislocation channeling deformation mode. Strong interactions between dislocation channels and voids are observed. 440 A typical pattern (Fig. 10 left images) is the activation of two different slip systems. One of them (indicated by the blue line) has the highest Schmid factor under the assumption of uniaxial stress state (as for the reference material), and the associated channel crosses almost the entire grain. The other activated to have a slip direction belonging to the slip plane of the other slip system. These features are recurrent in all situations observed at low applied macroscopic strain, and will be discussed in Section 4. It was not possible to characterize nucleation and propagation of these channels. As a consequence of dislocation channeling, void growth is discontinuous, and potentially severe considering the very low level of macroscopic applied strain. The distance between slip traces tends to be closer as the deformation increases. Figure 11 shows voids in the coalescence regime for two different pairs of voids. Distance between slip traces is very low compared to the distance far from the voids. Voids shape after coalescence tends to be similar to what is typically observed in materials deforming homogeneously [68, 82]. At the very end of one test (Fig. 11]), a crack 


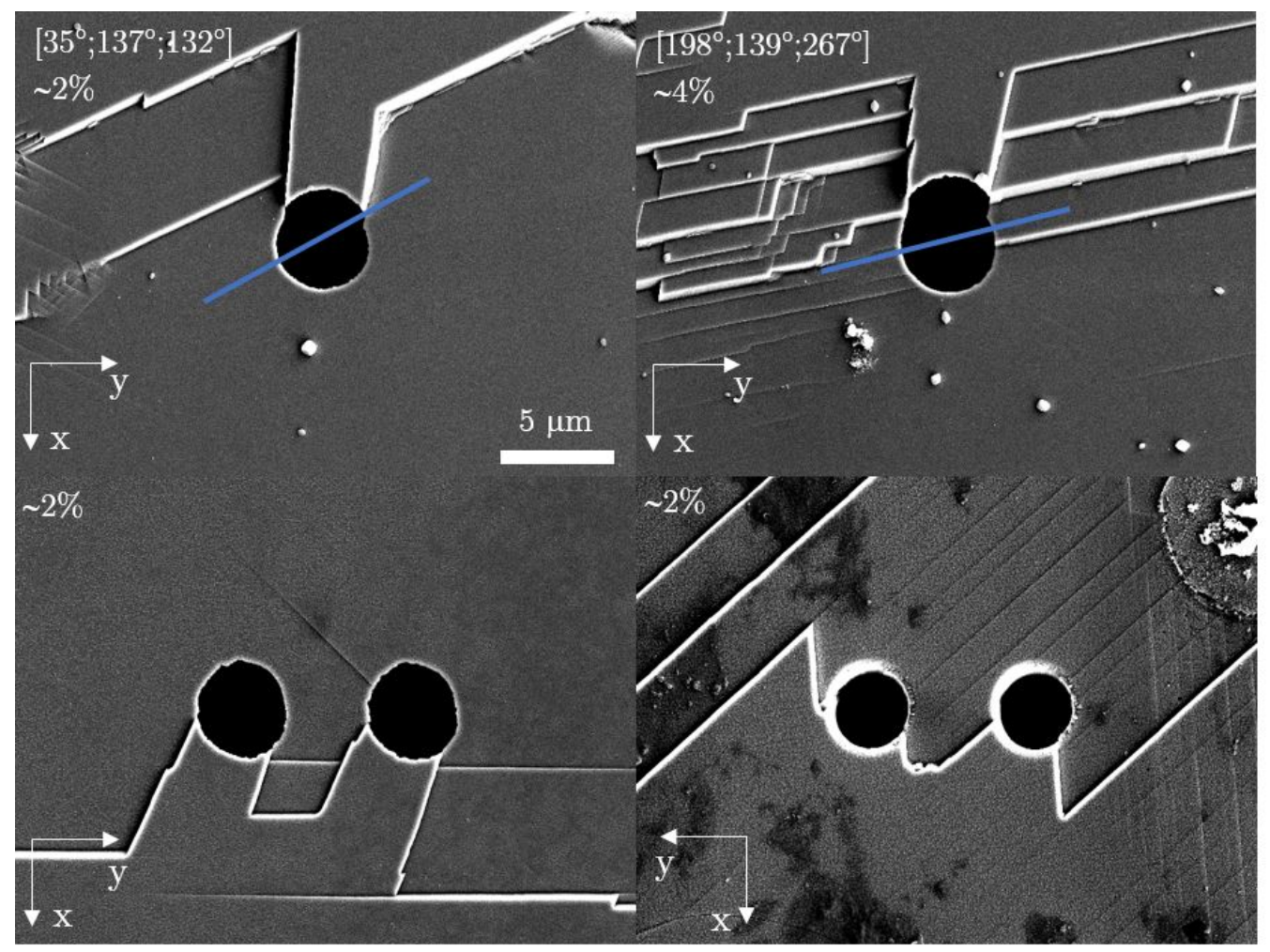

(a)

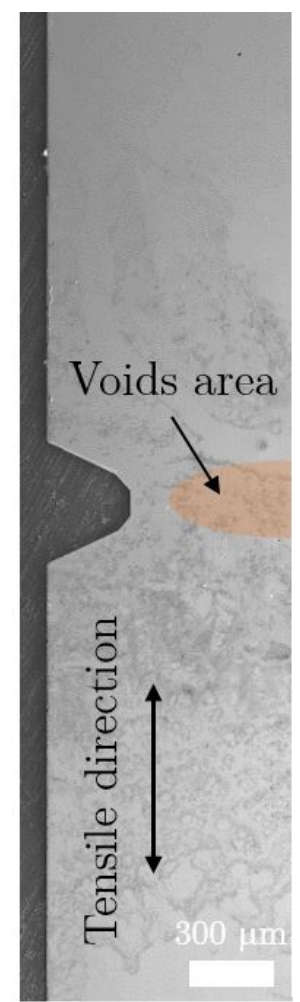

(b)

Figure 10: (a) Characteristic slip patterns around voids in material exhibiting dislocation channeling deformation mode. Each image corresponds to different grains: Euler angle orientation (given with the Bunge convention [zx'z"]) are obtained by EBSD analysis on the other side of the sample. Average strain levels along the tensile direction (along the $x$ axis) are evaluated using displacements measured at the boundaries of the images and a reference length equals to the images' height. Blue line is the intersection between the surface and the slip plane of the slip system having the highest Schmid factor calculated assuming uniaxial stress state and computed on the undeformed configuration. (b) Visualisation of half of the irradiated thin tensile sample, showing the area where voids have been drilled and notch geometry used to localize plasticity.

that initiates from the sample notch propagates towards the region where voids were drilled. The particular shape of the voids for $35 \%$ strain is attributed to the crack coming across the voids.

Experimental results indicate a strong effect of dislocation ${ }_{485}$ channeling deformation mode on voids evolution in single grains subjected to uniaxial stress conditions. A clear interaction between dislocation channels and voids is observed through the appearance of characteristic deformation patterns. As applied strain increases, additional channels are activated, leading to 490 more homogeneous deformation mode. Upon coalescence that corresponds to interactions between adjacent voids and thus to deviation from uniaxial stress loading conditions between the voids and higher local strains - the effect of dislocation channeling on voids evolutions weakens. These results are discussed 495 in the next section with respect to ductile fracture modeling 45 through void growth to coalescence in material exhibiting dislocation channeling deformation mode, as well as compared to numerical simulations.

\section{Discussion}

\subsection{From dislocation channeling to homogeneous deformation}

For low applied strain, a clear difference regarding voids evolution has been observed between the reference material that has an homogeneous deformation mode and the irradiated material having a dislocation channeling mode. For the latter case, a characteristic dislocation channels pattern has been observed where two slip systems are activated. In most situations (where there is only one grain through the thickness), the pattern observed on one side corresponds to point symmetry to the one observed on the other side where the homothetic center appears to be close to the middle of the sample, at the center of the void (or at the middle of the intervoid line for the cases with two voids). In addition, another interesting feature is that the channels corresponding to the slip system with the highest Schmid factor (Fig. 11 a) are often observed at some distance $\delta$ from the voids, typically on the order of void diameter. These observations can be rationalized as follows. Assuming that the primary activated slip system is the one with the highest Schmid factor in uniaxial stress conditions, the slip plane normal is oriented at about $45^{\circ}$ from the loading direction, defining a family of potential slip planes as sketched in Fig. 12. The intersections between these planes and the sample surfaces correspond to the steps observed in the experiments, which are related through a point symmetry from one side to the other. The position of the homothetic center can be understood as follows. For a voided plate subjected to a far field uniaxial tension state, local stresses 

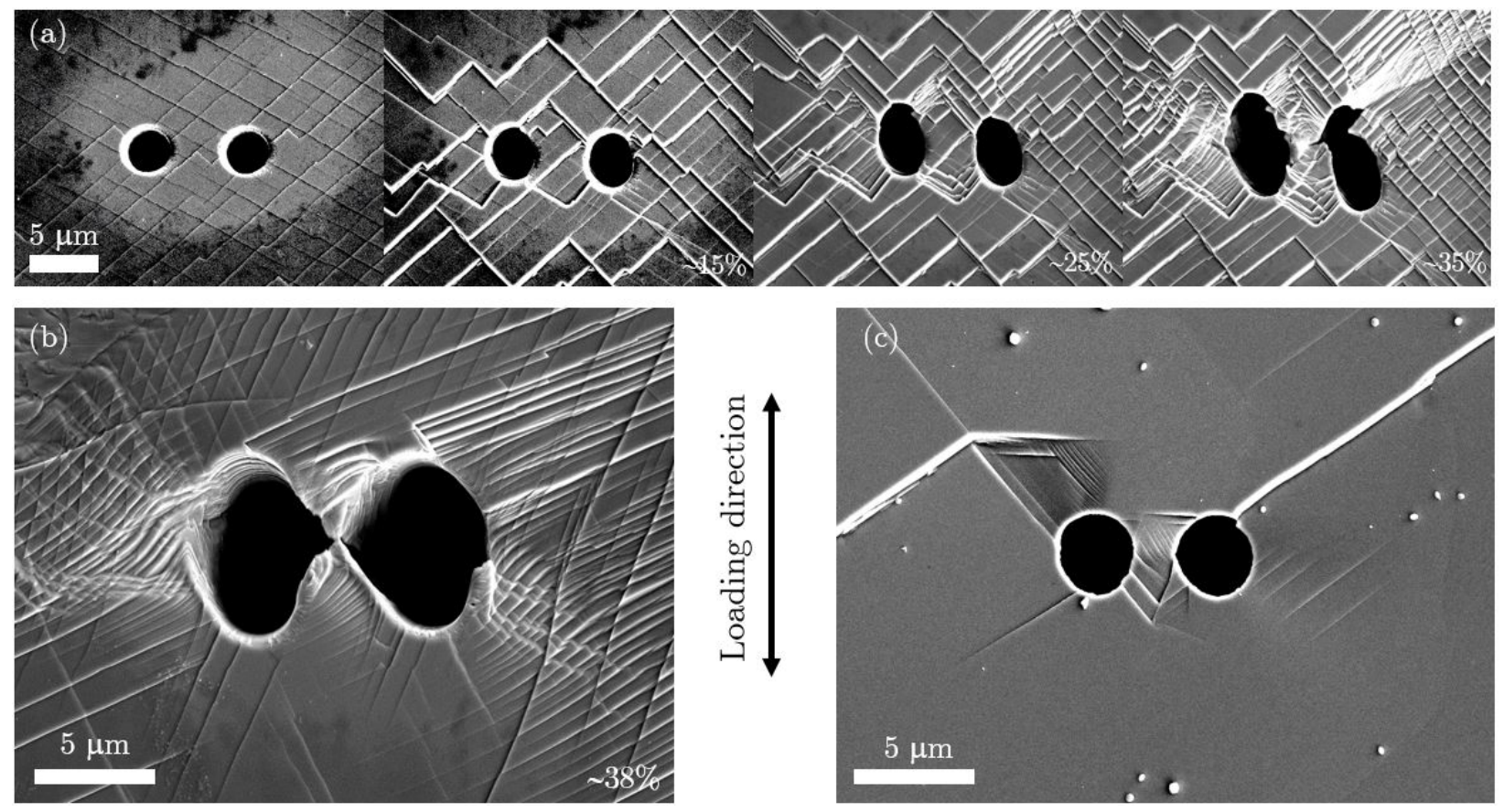

Figure 11: Typical observations of voids coalescence in the material exhibiting dislocation channeling deformation mode

close to the void deviate from the imposed loading conditions due to the presence of free surfaces. As sketched on Fig. 12 . regions above and below the void (in blue in Fig. 12) are essentially stress-free, while stress concentration along the tensile axis appears in other regions (in red), with a stress concentration factor of three for elastic isotropic material [83]. In addition, in these regions, stresses are expected to be higher at mid-thickness of the specimen than close to the surface where the sample free surfaces impose plane stress conditions. Therefore, plasticity is expected to initiate in that particular area. Due to high probability to find well-oriented (or almost) slip system in a FCC material, plastic slip will occur on a plane oriented at $45^{\circ}$ from the loading direction: two limit cases are illustrated in Fig. 12 with the corresponding slip traces at the surface which explains the experimental observations shown on Fig. 11]. For the case 1 , these surface traces will appear at a distance from the void center equal to $\delta \approx h / 2 \approx \phi$, as observed experimentally, but not in the stress-free region where no driving force exists for dislocation motion.

The number of surface steps increases with increasing applied strain, indicating that the primary channels do not have ${ }_{54}$ the ability to accommodate plasticity anymore. As the channels cross the entire grain, the multiplication of channels may be related to their impingement at grain boundaries where interactions with the adjacent grains lead to back stresses preventing further deformation. In addition, channels multiplication is par- ${ }_{545}$ ticularly observed in between voids at coalescence. This may be related to the numerical results described recently in [58] where localized plastic flow in irradiated materials was found to be suppressed in presence of high dislocation density and/or to the activation of multiple slip systems. At low applied strain, ${ }_{550}$ dislocation density is low and single slip is promoted due to the

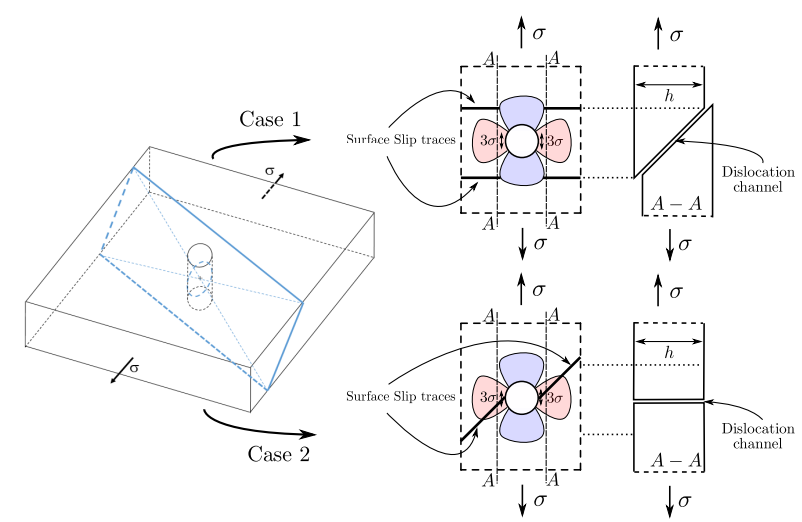

Figure 12: Schematic of slip planes oriented at $45^{\circ}$ from the loading direction and stress field around a cylindrical void inside a plate subjected to uniaxial stress loading conditions

uniaxial stress state imposed on non symmetric crystallographic orientations. Both conditions are expected to trigger localised plastic flow, as detailed in [58]. As applied strain increases, the increase of dislocation density and more importantly the interactions between adjacent voids leading to complex stress/strain fields requiring in general multiple slip activity tend to weaken localized plastic flow.

Besides the physical mechanism, multiplication of the dislocation channels around voids detailed in the experimental results (Fig. 11) clearly indicates a gradual clearance of irradiation defects over an extended area, leading to a deformation mode that becomes more and more homogeneous at the void scale. Such observation has implications for ductile fracture through void growth to coalescence modeling in irradiated materials, where dislocation channeling, although important at low 


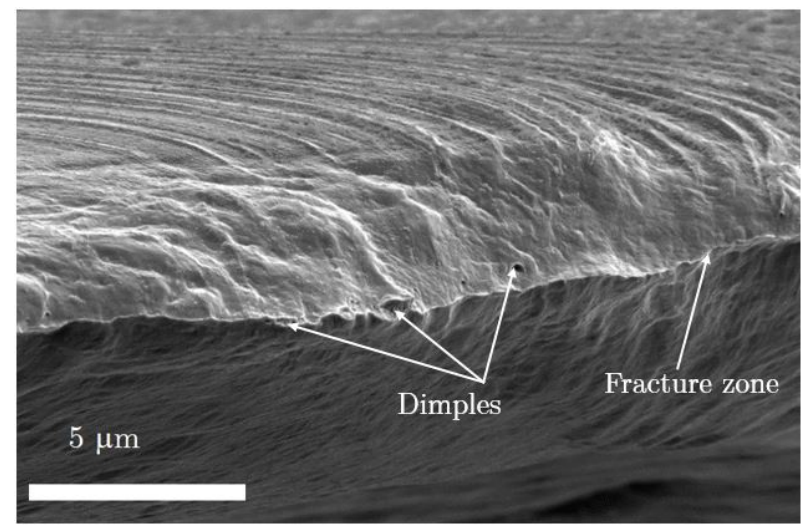

(a)

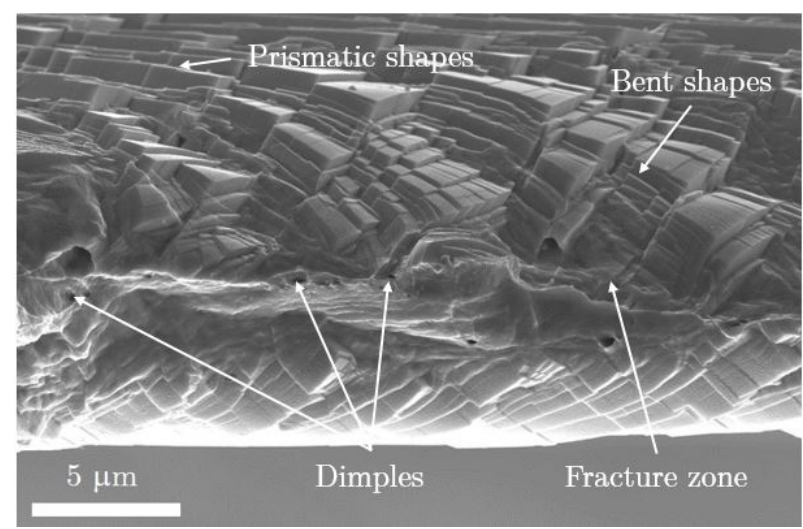

(b)

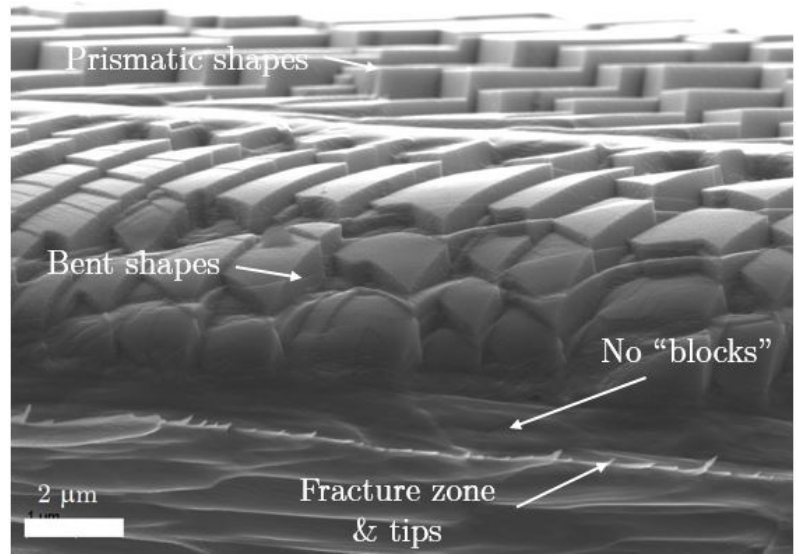

(c)

Figure 13: SEM observations of fracture regions of the thin tensile samples, $(\mathrm{a})^{605}$ for the reference material and $(b, c)$ for the irradiated material

applied strain, is gradually less operating with increasing strain. In order to assess this statement further - which is relevant for the description of voids impingement (Fig. 11) - fracture surfaces of the tensile samples (both reference and irradiated ones) have been observed with SEM.

Fracture occurs through almost complete necking in both reference and irradiated material with very limited fracture surfaces (Fig. 13). Few dimples are present, showing rare void

samples thus to a low density of inclusions. In the reference material (Fig. 13a), deformation mode is found to be homogeneous. On the contrary, the irradiated material shows traces of localized plastic flow (Fig. 13 b,c). Interestingly, different deformation modes are observed depending on the distance from the fracture surface. Far from the fracture surface and outside the necking region, undeformed prismatic blocks are observed (Fig. 13p), indicating that plasticity was localized in the channels in between these blocks. Far from the fracture surface but in the necking region, these prismatic blocks have a bent shape (Fig. 13k), which means that plastic deformation does not only appear in between the blocks through localized plastic flow, but also inside the blocks. This indicates that the multiplication of channels is not the only mechanism leading to more homoge-

575 mode appears in between channels. In the immediate vicinity of the fracture surface, prismatic blocks seem to disappear due to the high level of plastic strain, and deformation is homogeneous down to very low scales (as can be observed on the found to be also in line with the numerical results proposed in [58], especially regarding the ability of multiple slip activation (necessary in the necking region due the complex stress/strain states) to suppress localized plastic flow.

As deformation mode gradually moves from localized to homogeneous, this raises the question of using continuous plasticity framework to model ductile fracture through void nucleation, growth and coalescence in irradiated materials. Although not assessed in this study, void nucleation is expected to be influenced by dislocation channeling that may lead to severe local plastic strain and create voids, e.g., following a mechanism described in [84]. However, void growth and coalescence, mostly concerned with large strains and high stress triaxiality (that somehow weakens localized plastic flow), are expected tion mode as shown by the experimental results obtained in this study. Therefore, these results argue for a simplified modelling of ductile fracture in materials exhibiting dislocation channeling by using models derived under the assumption of homo600 sults presented in Section 3 can be used to assess, calibrate and improve crystal plasticity constitutive equations developed to describe the mechanical behavior of single crystals within the framework of continuum mechanics, for both reference material and for the material exhibiting dislocation channeling. The latter results could also serve as a test for Dislocation Dynamics simulations [34, 58] ability to reproduce the localization patterns. A complete study comparing numerical predictions to the experimental results is outside the scope of this study, but preliminary comparisons using crystal plasticity are given and discussed in the next section.

\subsection{Comparisons to numerical results}

As discussed in Section 2.2.2 the assumed uniaxial stress loading conditions at the grain scale can be applied to the unit cell used in the simulations assuming either periodic boundary conditions or static uniform boundary conditions (by adding 


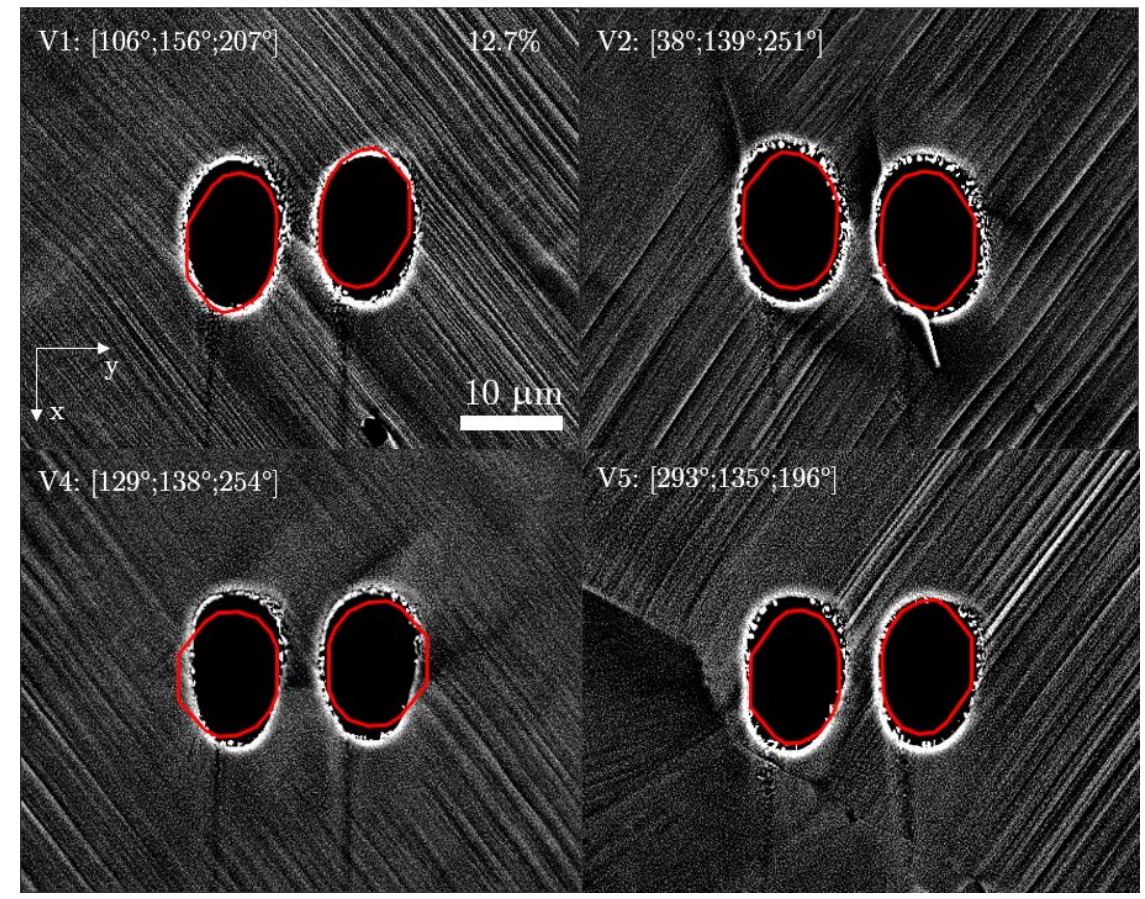

(a)
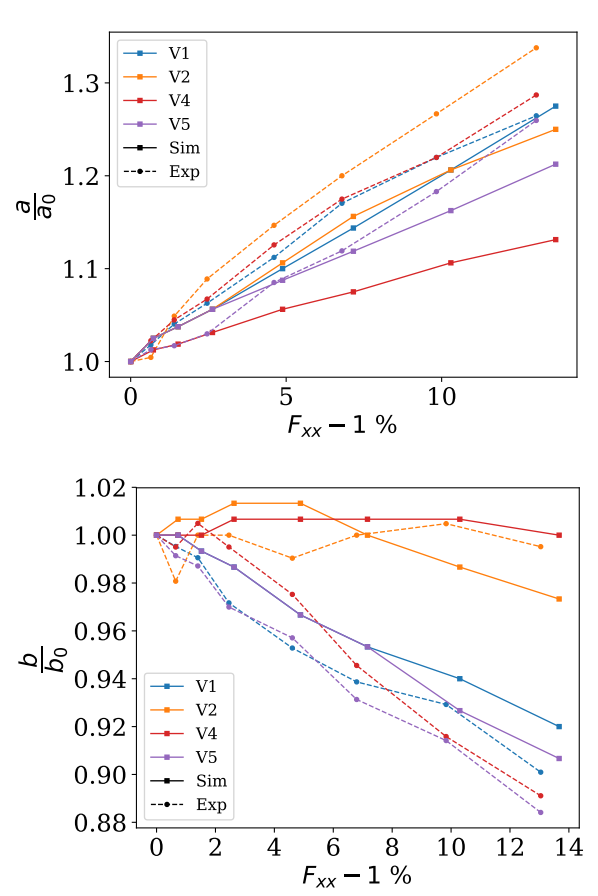

(b)

Figure 14: (a) Comparisons between experimental and numerical (red lines) voids shapes for different crystallographic orientations (b) Evolution of voids axis $a$ and $b$ (defined as the axis of an ellipse inscribed in the voids Fig. 7) as a function of engineering strain (denoted $F_{x x}-1=\Delta l / l_{0}$, with $l_{0}$ the initial gage lenth of the tensile sample, and $\Delta l$ the elongation) for the reference material: Comparisons between experimental (dashed lines) and numerical (solid lines) result for different void pairs (V1,V2,V4 and V5).

free surfaces). Experimental results on the reference material ${ }_{645}$ show that the influence of the presence of the voids on plasticity is rather weak, justifying the use of periodic boundary the been applied for the simulations of voids evolutions in the reference material. The comparisons of the predicted deformed void shapes and void axis evolution ${ }_{650}$ as a function of the engineering plastic strain along the tensile axis to the experiment results are shown on Fig. 14. For V1, V2 and V5, simulations reproduce fairly accurately both voids shapes and voids axis evolution, with no adjustable parameter, capturing the influence of crystallographic orienta-655 tions observed between voids V2 and V1 (or V5). For voids V4, the results do not match the experiments. Figure 15 shows ( $\left.\gamma^{s}\right)$ in each slip system with a pie chart plotted for each voxel of the simulation. The surface of the pie chart is also proportional to the sum of the cumulative ${ }_{660}$ plastic strain $\sum\left|\gamma_{s}\right|$. It is shown that far from the voids, only one system is activated, which corresponds to the experimental oservations. Moreover, the activated slip system in the simulations corresponds to the slip traces of the activated slip system in the experiments. Other slip systems are activated in some 665 areas close to the voids, especially for voids V2, which is not observed in the experiments.

As an intermediary conclusion, the use of crystal plasticity constitutive equations for FCC crystals appears to lead to rather satisfactory predictions in comparisons to experimental ${ }_{670}$ results on the reference material, with some noticeable discrepancies that may be related to numerical assumptions, especially
(1) uniaxial stress conditions that may be not relevant in some grains due to the interactions with other grains and/or (2) the definition of engineering plastic strain which is the macroscopic one for the experimental results but local one (at the grain scale) for the numerical results.

For the irradiated material, experimental results clearly indicate a localization pattern at the grain scale, so that periodic boundary conditions - that prevents such localization - can not be used. Therefore, simulations have been performed using free surfaces at the boundaries of the unit cell, mimicking the weak constraint imposed by the surrounding grains on the deformation behavior. Fig. 16 shows the typical results using the crystal plasticity softening behavior described in Section 2.2.2 using the crystallographic orientation of the grain shown in Fig. 10 up-left image. Cumulated plastic slip defined as $\sum\left|\gamma_{s}\right|$ is plotted to visualize plastic localization and to compare to experimental results. Using a pure softening law $\left(\Delta \tau_{2}=0\right.$ in Eq. 16$)$, a localization pattern is observed (Fig. 16(a) where two principal bands appear close to the void boundary. These bands correspond to the activation of only one slip system which is the one having the highest Schmid factor. Interestingly, as observed experimentally, a second band is observed linking the void and the main slip band in the same way observed in the experiments. However, the slip system contributing to this second band does not correspond to the slip system activated in the experiments. Using the softening-hardening law (Eq. 3 with $\Delta \tau_{2} \neq 0$ ), the localization pattern observed in Fig. 16 first appears, and then bands spread out, leading to a transition from dislocation chan- 


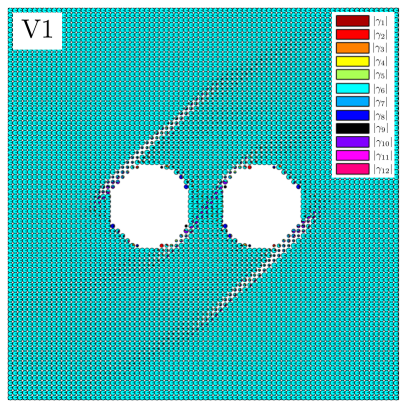

(a)

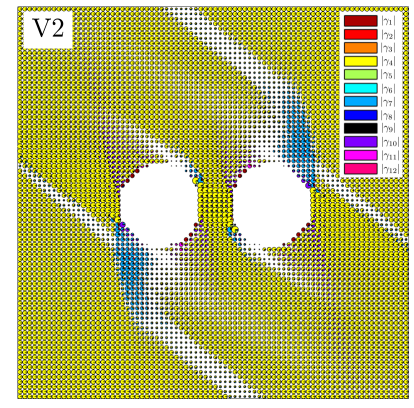

(b)

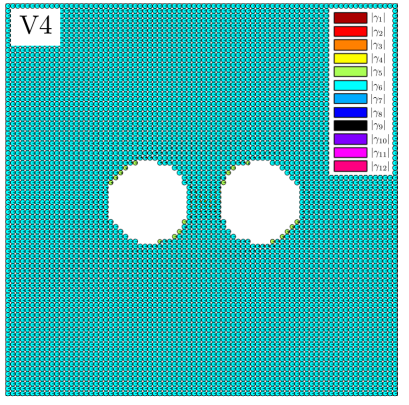

(c)

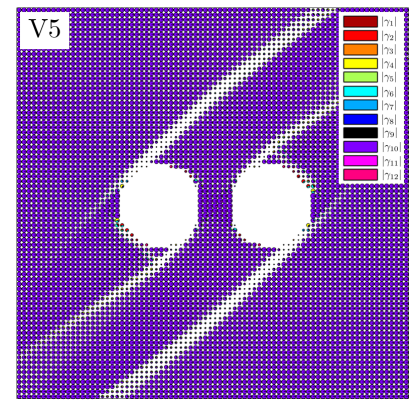

(d)

Figure 15: Proportion of the activated slip systems $\left(\left|\gamma_{s}\right|\right)$ close to the voids and at the surface of the sample, represented by a pie chart in each voxel of the simulation. Surface of the pie chart is proportional to $\sum\left|\gamma_{s}\right|$, (a) V1 (b) V2 (c) V4 (d) V5. Far from the voids (not shown here) only one slip system is activated

neling deformation mode to homogeneous deformation mode observed in the experiments, although nucleation of secondary695 bands can not be reproduced with such simple modeling.

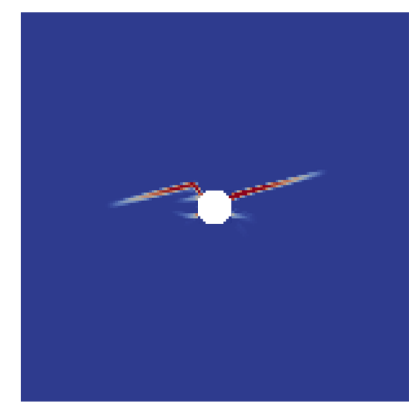

(a)

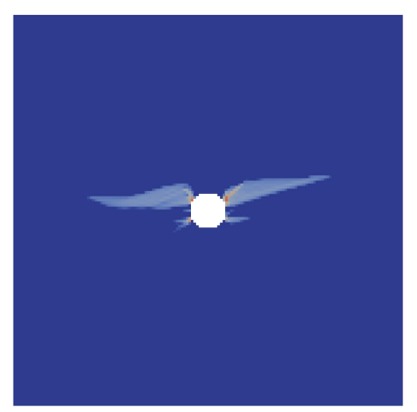

(b)
Figure 16: Cumulated plastic slip defined as $\sum\left|\gamma_{s}\right|$ resulting from the simulation710 of a FCC single crystal under uniaxial stress loading conditions (accounting for free surfaces), using the hardening law described in Eq. 3 with (a) $\Delta \tau_{2}=0$ and (b) $\Delta \tau \neq 0$, for the crystallographic orientation corresponding to Fig. 10 a up left image

\section{Conclusions and Perspectives}

Homogenized models developed for porous materials in the context of ductile fracture modeling assume implicitly homogeneous deformation mode at void scale in the sense that no strain localization appears at a lower scale. However, some materials such as metals quenched, heavily cold-worked or irradiated do present heterogeneous deformation mode at the grain scale related to the presence of defects. The so-called dislocation channeling deformation mode is almost always observed in irradi- ${ }_{725}$ ated materials that fail in most cases through a void growth to coalescence fracture mechanism. The influence of dislocation channeling deformation mode on void growth to coalescence has been studied experimentally based on model experiments at the grain scale, through comparisons to a reference material deforming homogeneously. In both cases, an influence of crystallographic orientation on voids evolutions under mechanical loading is observed, consistent with previous studies. A strong effect of dislocation channeling on voids evolutions is observed at low applied strain through the appearance of characteristic channels patterns interacting with voids. However, gradual activation of secondary dislocation channels tends to lead to more and more homogeneous deformation mode with increasing applied strain. These observations have been made on low stress triaxiality tests, but the effect of dislocation channeling mode 700 is expected to be even weaker for higher stress triaxiality for which multiple slip is activated. The experimental results argue for a simplified modelling of ductile fracture in materials showing a propensity to localization at the grain scale due to dislocation channeling deformation mode, at least when fracture is 05 driven by void growth to coalescence, by using homogenized models for porous materials developed for materials deforming homogeneously. For materials where fracture is driven mainly through void nucleation, an influence of dislocation channeling may be expected, due to potential local high stresses / strains, that remains to be studied.

Comparisons of experimental to numerical results regarding voids deformations in FCC single crystals performed in this study indicate that the use of crystal plasticity constitutive equations is able to reproduce quantitatively some experimental oband (partly) the localization pattern for the dislocation channeling material. However, for the reference material, a good agreement is observed by using boundary conditions inferred from experimental observations, i.e., periodic boundary conditions that prevents strong localization. Interestingly, more realistic simulations for the reference material that consider a 2D polycrystalline aggregate with free surfaces with voids at the grain scale lead to strong localization through the appearance of a slip band crossing the voids, which is not observed in the experiments. Such localization is in fact rooted in the crystal plasticity constitutive equations used where the parameters $\kappa$ and $G_{c}$ have been calibrated through comparisons to a tensile curve on a polycrystalline aggregate. The values of the parameters lead to a softening behavior in the case of single slip, thus localization in the case of uniaxial stress state. This emphasizes the fact that calibration of crystal plasticity constitutive equations should be performed at the single crystal scale to lead to quantitative - and even qualitative - behavior consistent with experimental results. For the material exhibiting 
channeling, the use of an ad-hoc softening behav- 700 ior mimicking more complicated formulations proposed in previous studies reproduces somehow the localization pattern and phenomenologically the transition between localization and homogeneous deformation mode. However, such simple model-

740 ing can not trigger the gradual activation of additional channels 775 which deserves attention in further studies with respect to physical mechanism involved and numerical modeling.

Finally, interactions between dislocation channels and voids have been studied for voids sizes $(\sim 1 \mu \mathrm{m})$ larger than chan(as shown in Appendix A) of typical sizes lower than channels widths, another kind of interaction can also be observed, as shown in Fig. 17, where nanovoids deform inside a dislocation channel. A full description of such phenomenon, as well as the potential implication regarding ductile fracture of irradiated materials, remain to be studied.

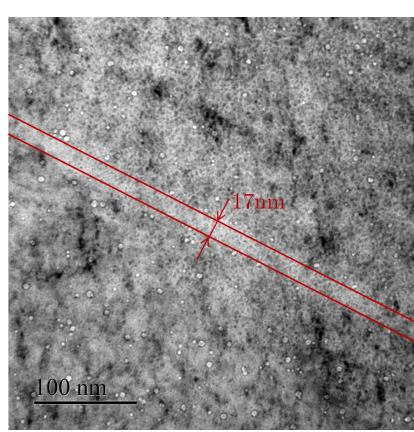

(a)

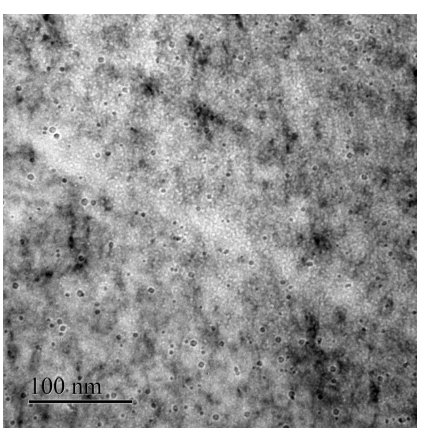

(b)
Figure 17: TEM observations of interactions between nanovoids and a dislocation channel under (a) underfocus condition where voids are white spots surrounded by a black line and (b) overfocus conditions where voids are black spots surrounded by a white line. Voids are not observed inside the channel as a consequence of void rotation and closure under large shear strain

\section{Acknowledgements}

The authors would like to thank Véronique Cloute Cazalaa and Elodie Rouesne for their help with Scanning Electron Microscope observations, and Lionel Gélébart for the use of the AMITEX_FFTP solver. This project has received funding from the Euratom research and training programme 2014-2018 un-78 der Grant Agreement $\mathrm{N}^{\circ} 661913$. This work reflects only the authors' view and the Commission is not responsible for any use that may be made of the information it contains.

\section{Appendices}

\subsection{Appendix A: Irradiated material}

The microstructure of the irradiated material has been characterized through Transmission Electron Microscopy (TEM) observations performed on a FEI Tecnai G2 300kV. Disk-shape thin foils (diameter $3 \mathrm{~mm}$, thickness $100 \mu \mathrm{m}$ ) sampled at the surface of an irradiated specimen have been obtained by mechanical polishing. Electrolytic polishing finally allows to get areas of thickness about 100nm that can be observed by TEM.
Typical bright and dark fields TEM observations are shown on Fig. 18(a,b), showing two types of irradiation defects, namely nanovoids and faulted dislocations loops / Frank loops that lie in (111) planes. Frank loops are observed in dark field condition by selecting $g=1 / 2(\overline{3} 11)$, while voids are differentiated from over microstructural features using underfocus / overfocus observations. Size distributions of voids and Frank loops are shown on Fig. $18(\mathrm{c}, \mathrm{d})$, with average sizes of $3.7 \mathrm{~nm}$ and $6.1 \mathrm{~nm}$, respectively. Assuming a mean thickness of the TEM foils of $150 \mathrm{~nm}$, voids and Frank loops densities have been evaluated to $2.010^{21} \mathrm{~m}^{-3}$ and $5.310^{22} \mathrm{~m}^{-3}$, respectively.

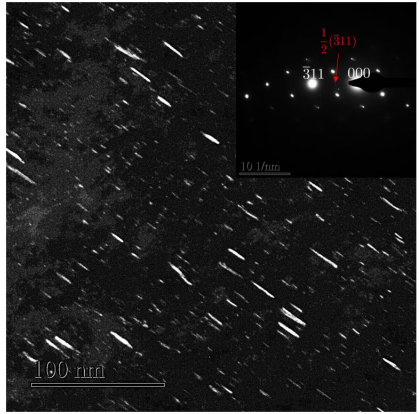

(a)

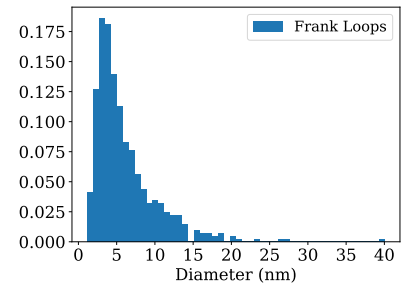

(c)

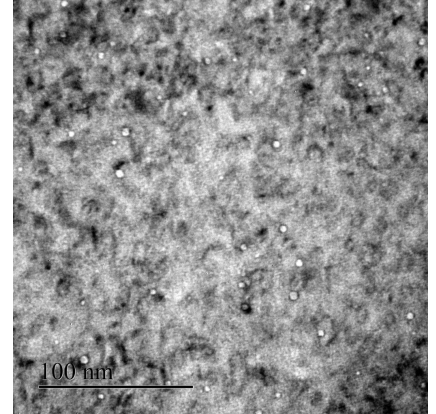

(b)

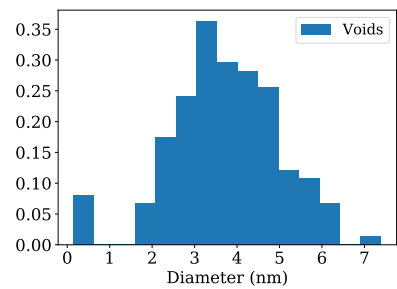

(d)
Figure 18: (a) Dark Field TEM image (obtained by selecting $g=1 / 2(\overline{3} 11)$ ) allowing to observe Frank loops (b) Bright Field TEM images showing the presence of nanovoids. (c,d) Size distribution of Frank loops and nanovoids

The Vickers hardness of irradiated samples has been measured to be $310 \pm 14 \mathrm{HV}_{0.02}$ using the same conditions as for the reference state ( $20 \mathrm{~g}$ with $10 \mathrm{~s}$ hold time). The increase of hardness is thus equal to $\Delta \mathrm{H}_{\mathrm{V}}=117$, in agreement with the Frank loop density and size measured (as the major contributor to hardening) following the correlation explained for example in [85].

\subsection{Appendix B: Numerical simulations}

Numerical simulations using crystal plasticity constitutive equations (detailed in Section 2.2.2) and compared to experimental results have been performed using AMITEX_FFTP Fast Fourier Transform based solver [72]. This numerical method, first introduced by [86], relies on structured grids (composed of voxels) subjected to periodic boundary conditions where the displacement field $\underline{u}$ is:

$$
\underline{u}(x)=[\underline{\mathbf{F}}-\underline{\mathbf{1}}] \underline{x}+\underline{u}^{\star}(x)
$$


where $\mathbf{F}$ is the macroscopic (volume average) deformation graformation gradient $\underline{\mathbf{F}}$ can be prescribed, or either macroscopic Cauchy stress $\underline{\sigma}$ (through finding the corresponding macroscopic deformation gradient by an iterative procedure). A finite strain extension of the original FFT method is implemented in AMITEX_FFTP by solving the equilibrium equation using first Piola-Kirchhoff stress tensor on the reference (undeformed) configuration [72]. Each voxel of the structured grid can be assigned different constitutive equations. The code generator MFront [87] has been used to implement the finite strain crystal plasticity constitutive equations. Details about the implementation can be found in [74, 81].

Although FFT method relies on unit cell subjected to periodic boundary conditions, free surfaces can easily be added by considering stress-free voxels at the boundaries of the unit cell, as shown on Fig. 19 a.

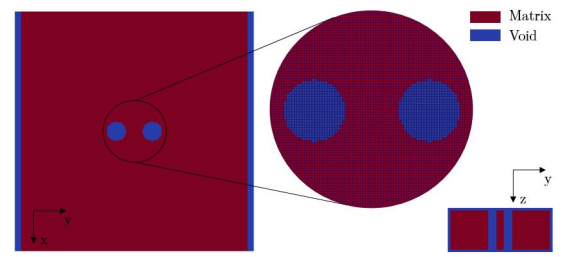

(a)

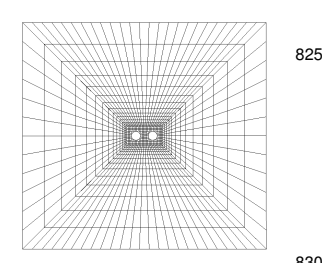

(b)
Figure 19: (a) FFT discretization of a plate with two cylindrical voids subjected to uniaxial stress loading conditions by adding free surfaces. (b) Corresponding Finite Element mesh

As a validation test, a FFT simulation of a plate with two cylindrical holes is performed under uniaxial loading conditions (Fig. 19 assuming von Mises plasticity with isotropic hardening $(R(p)=$ ${ }_{810} R_{0}+Q_{1}\left[1-\exp \left(-b_{1} p\right)\right] . \quad\left\{R_{0}=126 \mathrm{MPa}, Q_{1}=219 \mathrm{MPa}\right.$ $\left.\left.b_{1}=7\right\}\right)$, and the evolutions of void axis $\{a, b\}$ are compared to reference results obtained in [82] with the Finite Element840 Method (FEM). Details about the reference simulation can be found in [82], and a typical mesh used in shown on Fig. 19p. Stress-free voxels are used for the voids and also to model free surfaces (on all side of the cell except along the tensile direction), as shown on Fig. 19 A. Average deformation gradient is ${ }_{845}$ applied along the tensile direction. As for finite element simulations, cumulative plastic strain is measured far from the voids. Size of the normalized axis $a$ and $b$ as a function of the far field plastic strain are compared in Fig. 20. Results show a good agreement between both FFT and FEM simulations, validating the use of FFT solver considering free surfaces.

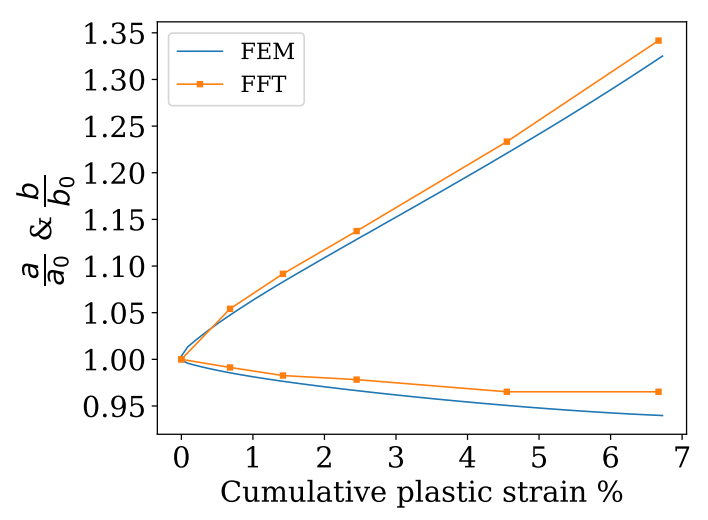

Figure 20: Evolution of voids axis $a$ and $b$ (defined as the axis of an ellipse inscribed in the voids) as a function of far field plastic strain. Comparisons between reference results from [82] obtained by the Finite Element method (FEM) to FFT simulations

For all simulations performed in this study, structured grids shown in Figs. 6 and 19 a are used. Stress-free constitutive equations are assigned to the voxels corresponding to the cylindrical voids (and to the free surfaces for Fig. 19 a), while crystal plasticity constitutive equations (described in Section 2.2.2) are assigned to the remaining voxels. Orientation of the crystal is given by the experimental EBSD analysis. Deformation gradient $F_{x x}$ along the tensile axis is prescribed, and all Cauchy stress tensor components - except $\sigma_{x x}$ - are set to zero to model uniaxial stress state. Convergence with respect to the number of voxels used has been carried out, and 301 voxels are typically used along the in-plane length. As FFT method computes only deformation gradient and stress tensors for each voxel, a post,processing is applied to recover displacement field by solving the compatibility equation [72], leading to the evolution of void size as a function of the prescribed deformation gradient.

\subsection{Appendix C: Observation of dislocation channels}

A Transmission Electron Microscope (TEM) sample was extracted (using FIB lift-up technique) perpendicular to the steps observed on sample surface, as shown in Fig. 21(a) TEM observation shows that these steps correspond to narrow bands where Frank loops irradiation defects have been largely removed, thus appearing clear on TEM bright field images (Fig. 21(b)). The typical channel width is about $20 \mathrm{~nm}$ or less. As the steps of the channels on the sample surface can be estimated to be about $1 \mu \mathrm{m}$ high, shear strain can be evaluated to be about $5000 \%$. 


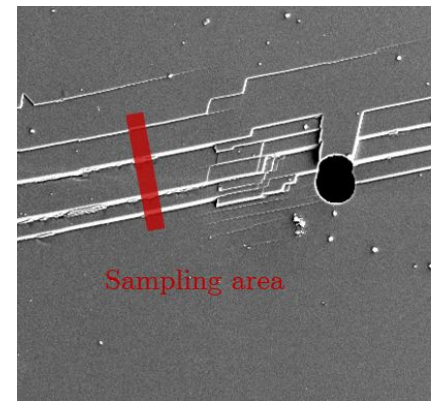

(a)

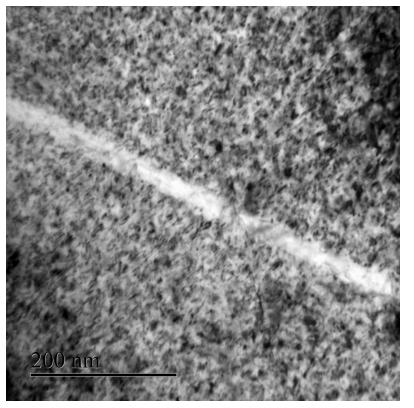

(b)
Figure 21: (a) Sampling of the TEM foil (b) Bright Field TEM image at the 910 location of a step, showing a narrow band where irradiation defects have been partially removed

\section{Data availability}

The raw/processed data required to reproduce these findings cannot be shared at this time due to technical or time limitations.

\section{References}

[1] A. Pineau, A. A. Benzerga, T. Pardoen, Failure of metals I: Brittle and ${ }^{925}$ ductile fracture, Acta Mat. 107 (2016) 424-483.

[2] C. F. Tipper, The fracture of metals, Mettalurgia 39 (1949) 133-137.

[3] K. E. Puttick, Ductile fracture in metals, Phil. Mag. 4 (1959) 964-969.

[4] A. S. Argon, J. Im, R. Safoglu, Cavity formation from inclusions in ductile fracture, Metallurgical Transactions A 6A (1975) 825-837.

[5] F. A. McClintock, A criterion for ductile fracture by the growth of holes, J. App. Mech. 35 (1968) 363-371.

[6] J. R. Rice, D. M. Tracey, On the ductile enlargement of voids in triaxial stress fields, J. Mech. Phys. Solids 17 (1969) 201-217.

[7] L. M. Brown, J. D. Embury, The initiation and growth of voids at sec- ${ }^{935}$ ond phase particles, Vol. 3rd International Conference on the strength of metals and alloys, 1973, pp. 164-168.

[8] J. Koplik, A. Needleman, Void growth and coalescence in porous plastic solids, Int. J. Solids Struct. 24 (1988) 835-853.

[9] V. Tvergaard, Material failure by void growth to coalescence, Adv. Ap- ${ }^{940}$ plied Mech. 27 (1990) 83-151.

[10] S. Keralavarma, S. Hoelscher, A. Benzerga, Void growth and coalescence in anisotropic solids, Int. J. Solids Struct. 48 (2011) 1696-1710.

[11] B. Legarth, V. Tvergaard, Effects of plastic anisotropy and void shape on full three-dimensional void growth, J. App. Mech. 85 (2018) 051007.

[12] D. M. Tracey, Strain hardening and interaction effects on the growth of voids in ductile fracture, Eng. Fract. Mech. 3 (1971) 301-315.

[13] L. Lecarme, C. Tekoglu, T. Pardoen, Void growth and coalescence in ductile solids with stage III and stage IV strain hardening, Int. J. Plasticity 27 (2011) 1203-1223.

[14] Y. Alinaghian, M. Asadi, A. Weck, Effect of pre-strain and work hardening rate on void growth and coalescence in AA5052, Int. J. Plasticity 53 (2014) 193-205.

[15] A. Hosokawa, D. S. Wilkinson, J. Kang, M. Kobayashi, H. Toda, Void growth and coalescence in model materials investigated by high- ${ }^{955}$ resolution X-ray microtomography, Int. J. Frac. 181 (2013) 51-66.

[16] E. Maire, P. Withers, Quantitative X-ray tomography, Int. Mat. Rev. 59 (2014) 1-43.

[17] Y. X. Gan, J. W. Kysar, T. L. Morse, Cylindrical void in a rigid-ideally plastic single crystal II: Experiments and simulations, Int. J. Plasticity $22^{960}$ (2006) 39-72

[18] J. Crépin, T. Bretheau, D. Caldemaison, Cavity growth and rupture of $\beta$ treated zirconium: A crystallographic model, Acta Mat. 12 (1996) 4927 4935 .
[19] M. Pushkareva, J. Adrien, E. Maire, J. Segurado, J. Llorca, A. Weck, Three-dimensional investigation of grain orientation effects on void growth in commercially pure titanium, Materials Science and Engineering: A 671 (2016) 221-232.

[20] W. Liu, X. Zhang, J. Tang, Y. Du, Simulation of void growth and coalescence behavior with 3D crystal plasticity theory, Comp. Mat. Sci. 40 (2007) 130-139.

[21] S. Ha, K. Kim, Void growth and coalescence in f.c.c. single crystals, Int. J. Mech. Sci. 52 (2010) 863-873.

[22] S. Yerra, C. Tekoglu, F. Scheyvaerts, L. Delannay, P. Van Houtte, T. Pardoen, Void growth and coalescence in single crystals, Int. J. Solids and Structures 47 (2010) 1016-1029.

[23] C. Ling, J. Besson, S. Forest, B. Tanguy, F. Latourte, E. Bosso, An elastoviscoplastic model for porous single crystals at finite strains and its assessment based on unit cell simulations, Int. J. Plasticity 84 (2016) 58-87.

[24] A. A. Benzerga, J.-B. Leblond, Ductile fracture by void growth to coalescence, Adv. Applied Mech. 44 (2010) 169-305.

[25] A. Benzerga, J. Leblond, A. Needleman, V. Tvergaard, Ductile failure modeling, Int. J. Frac. 201 (2016) 29-80.

[26] A. Gurson, Continuum theory of ductile rupture by void nucleation and growth: Part I - Yield criteria and flow rules for porous ductile media, J. Eng. Mat. and Tech. 99 (1977) 2-15.

[27] P. F. Thomason, A three-dimensional model for ductile fracture by the growth and coalescence of microvoids, Acta. Metall. 33 (1985) 10871095 .

[28] A. Mbiakop, A. Constantinescu, K. Danas, An analytical model for porous single cristals with ellipsoidal voids, J. Mech. Phys. Solids 84 (2015) 436-467.

[29] D. Song, P. Ponte-Castañeda, A finite-strain homogenization model for viscoplastic porous single crystals. I-Theory, J. Mech. Phys. Solids 107 (2017) 560-579.

[30] D. Song, P. Ponte-Castañeda, A finite-strain homogenization model for viscoplastic porous single crystals. II-Applications, J. Mech. Phys. Solids 107 (2017) 580-602.

[31] J. Rice, The localization of plastic deformation, Vol. 14th International Congress on Theoretical and Applied Mechanics, 1976, pp. 207-220.

[32] J. Segurado, J. Llorca, An analysis of the size effect on void growth in single crystals using discrete dislocation dynamics, Acta Mat. 57 (2009) $1427-1436$

[33] J. Segurado, J. Llorca, Discrete dislocation dynamics analysis of the effect of lattice orientation on void growth in single crystals, Int. J. Plast. 26 (2010) 806-819.

[34] H. Chang, J. Segurado, J. Lorca, Three-dimensional dislocation dynamics analysis of size effects on void growth, Scripta Mat. 95 (2015) 11-14.

[35] L. Cheng, T. Guo, Void interaction and coalescence in polymeric materials, Int. J. Solids Struct. 44 (2007) 1787-1808.

[36] F. Smidt, Dislocation channeling in irradiated metals, Tech. rep., Naval Research Lab Washington DC (1970).

[37] M. Wechsler, Dislocation channeling in irradiated and quenched metals, Tech. rep., Ames Lab (1972).

[38] F. A. Garner, Radiation damage in austenitic steels, Comprehensive $\mathrm{Nu}$ clear Materials 4 (2012) 33-95.

[39] R. E. Stoller, Primary radiation damage formation, Comprehensive $\mathrm{Nu}$ clear Materials (2012) 293-333.

[40] C. Pokor, X. Averty, Y. Brechet, P. Dubuisson, J.-P. Massoud, Effect of irradiation defects on the work hardening behavior, Scripta Mat. 50 (2004) 597-600.

[41] O. K. Chopra, A. S. Rao, A review of irradiation effects on LWR core internal materials IASCC susceptibility and crack growth rates of austenitic stainless steels, J. Nuc. Mat. 409 (2011) 235-256.

[42] S. Zinkle, G. Was, Materials challenges in nuclear energy, Acta Mat. 61 (2013) 735-758.

[43] K. Farrell, T. Byun, N. Hashimoto, Deformation mode maps for tensile deformation of neutron-irradiated structural alloys, J. Nuc. Mat. 335 (2004) 471-486.

[44] T. Byun, N. Hashimoto, K. Farrell, Deformation mode map of irradiated 316 stainless steel in true stress-dose space, J. Nuc. Mat. 351 (2006) 303315.

[45] N. Hashimoto, T. Byun, K. Farrell, Microstructural analysis of deformation in neutron-irradiated fcc materials, J. Nuc. Mat. 351 (2006) 295-302.

[46] T. Byun, N. Hashimoto, Strain localization in irradiated materials, Nuc. 
Eng. Tech. 38 (2006) 619-638.

[47] T. Byun, N. Hashimoto, K. Farrell, E. Lee, Characteristics of microscopic strain localization in irradiated 316 stainless steels and pure vanadium, J. Nuc. Mat. 349 (2006) 251-264.

[48] M. McMurtrey, B. Cui, I. Robertson, D. Farkas, G. Was, Mechanism of dislocation channel-induced irradiation assisted stress corrosion crack initiation in austenitic stainless steel, Cur. Op. Solid State Mat. Sci. 19 (2015) 305-314.

[49] M. Bapna, T. Mori, M. Meshii, The observation of slip channels ino45 quenched gold, Phil. Mag. 17 (1967) 177-184.

[50] T. Mori, M. Meshii, Plastic deformation of quench-hardened aluminum single crystals, Acta Metallurgica 17 (2) (1969) 167 - 175.

[51] A. Luft, J. Richter, K. Schlaubitz, C. Loose, C. Mhlhaus, Work softening and microstructural instability of predeformed molybdenum single crys $\$ 050$ tals, Materials Science and Engineering 20 (1975) 113 - 122.

[52] Z. Jiao, J. Busby, G. Was, Deformation microstructure of protonirradiated stainless steels, J. Nuc. Mat. 361 (2007) 218-227.

[53] M. Gussev, K. Field, J. Busby, Deformation localization and dislocation channel dynamics in neutron-irradiated austenitic stainless steels, J. Nuc1055 Mat. 460 (2015) 139-152.

[54] M. Gaume, Etude des mécanismes de déformation des alliages de zirconium après et sous irradiation, Ph.D. thesis, Université de Toulouse, Université Toulouse III-Paul Sabatier (2017).

[55] S. Mahajan, B. Eyre, Formation of dislocation channels in neutron irradi 4060 ated molybdenum, Acta Mat. 122 (2017) 259-265.

[56] P. Doyle, K. Benensky, S. Zinkle, Modeling of dislocation channel width evolution in irradiated metals, J. Nuc. Mat. 499 (2018) 47-64.

[57] Y. Cui, G. Po, N. Ghoniem, A coupled dislocation dynamics-continuum barrier field model with application to irradiated materials, Int. J. Plastic 4065 ity 104 (2018) 54-67.

[58] Y. Cui, G. Po, N. Ghoniem, Suppression of localized plastic flow in irradiated materials, Scripta Mat. 154 (2018) 34-39.

[59] K. Gururaj, C. Robertson, M. Fivel, Channel formation and multiplication in irradiated FCC metals : a 3D dislocation dynamics investigation, Philio7o Mag. 95 (2015) 1368-1389.

[60] W. Mills, Fracture toughness of irradiated stainless steel alloys, Nuclear technology 82 (1988) 290-303.

[61] O. Chopra, A. Rao, A review of irradiation effects on LWR core internal materials-Neutron embrittlement, J. Nuc. Mat. 412 (2011) 195-208. 1075

[62] E. Lee, T. Byun, J. Hunn, K. Farrell, L. Mansur, Origin of hardening and deformation mechanisms in irradiated $316 \ln$ austenitic stainless steel, J. Nuc. Mat. 296 (2001) 183-191.

[63] D. Damcott, J. Cookson, V. Rotberg, G. Was, A radiation effects facility using a 1.7 MV tandem accelerator, Nuclear Instruments and Methods ino80 Physics Research Section B: Beam Interactions with Materials and Atoms 99 (1995) 780-783.

[64] G. Was, J. Busby, T. Allen, E. Kenik, A. Jensson, S. Bruemmer, J. Gan, A. Edwards, P. Scott, P. Anderson, Emulation of neutron irradiation effects with protons: validation of principle, J. Nuc. Mat. 300 (2002) 198216.

[65] J. F. Ziegler, M. D. Ziegler, J. P. Biersack, Srim-the stopping and range of ions in matter (2010), Nuclear Instruments and Methods in Physics Research Section B: Beam Interactions with Materials and Atoms 268 (2010) 1818-1823.

[66] R. Stoller, M. Toloczko, G. Was, A. Certain, S. Dwaraknath, F. Garner, On the use of SRIM for computing radiation damage exposure, Nuclear Instruments and Methods in Physics Reserch B 310 (2013) 75-80.

[67] ASTM E521, Standard practice for neutron radiation damage simulation by charged-particle irradiation, Annual Book of ASTM Standards.

[68] A. Weck, D. Wilkinson, Experimental investigation of void coalescence in metallic sheets containg laser drilled holes, Acta Mat. 56 (2008) 17741784.

[69] M. J. Nemcko, J. Li, D. S. Wilkinson, Effects of void band orientation and crystallographic anisotropy on void growth and coalescence, J. Mech. Phys. Solids 95 (2016) 270-283.

[70] F. Di Gioacchino, J. Q. da Fonseca, Plastic strain mapping with submicron resolution using digital image correlation, Exp. Mech. 53 (2013) $743-754$.

[71] R. Seghir, J. Witz, S. Coudert, Digital image correlation 2D/3D software, www.yadics.univ-lille1.fr.

[72] CEA, Amitex_fftp, www.maisondelasimulation.fr/projects/amitex/html/.
[73] L. Méric, G. Cailletaud, Single crystal modeling for structural calculations; Ppart 2 Finite element implementation, J. Eng. Mater. Technol. 113 (1991) 171-182.

[74] J. Hure, S. El Shawish, L. Cizelj, B. Tanguy, Intergranular stress distributions in polycrystalline aggregates of irradiated stainless steel, J. Nuc. Mat. 476 (2016) 231-242.

[75] X. Han, Modélisation de la fragilisation due au gonflement dans les aciers inoxydables austénitiques irradiés, Ph.D. thesis, Thèse CEA, Ecole nationale supérieure des mines de Paris soutenue le 16/03/2017 (2012).

[76] N. Barton, J. Arsenlis, A. ans Marian, A polycrystal plasticity model of strain localization in irradiated iron, J. Mech. Phys. Solids 61 (2013) 341351.

[77] S. De, Multiscale modeling of irradiated polycrystalline FCC metals, Int. J. Solids and Structures 51 (2014) 3919-3930.

[78] A. Gross, K. Ravi-Chandar, On the deformation and failure of al 6061-T6 in plane strain tension evaluated through in situ microscopy, Int. J. Frac. 208 (2017) 27-52.

[79] G. Potirniche, J. Hearndon, M. Horstemeyer, X. Ling, Lattice orientation effects on void growth and coalescence in FCC single crystals, Int. J. Plasticity 22 (2006) 921-942.

[80] W. Liu, X. Zhang, J. Tang, Y. Du, Simulation of void growth and coalescence behavior with 3D crystal plasticity theory, Computational Materials Science 40 (2007) 130-139.

[81] C. Ling, J. Besson, S. Forest, B. Tanguy, F. Latourte, E. Bosso, An elastoviscoplastic model for porous single crystals at finite strains and its assessment based on unit cell simulations, Int. J. Plasticity 84 (2016) 58-87.

[82] P. Barrioz, J. Hure, B. Tanguy, Void growth and coalescence in irradiated copper under deformation, J. Nuc. Mat. 502 (2018) 123-131.

[83] C. Inglis, Stresses in plates due to the presence of cracks and sharp corners, Transactions of the Institute of Naval Architects 55 (1913) 219-241.

[84] P. Noell, J. Caroll, K. Hattar, B. Clark, B. Boyce, Do voids nucleate at grain boundaries during ductile rupture, Acta Mat. 137 (2017) 103-114.

[85] J. Gupta, J. Hure, B. Tanguy, L. Laffont, M. Lafont, E. Andrieu, Characterization of ion irradiation effects on the microstructure, hardness, deforamtion and crack initiation behavior of austenitic stainless steel; Heavy ions vs. protons, J. Nuc. Mat. 501 (2018) 45-58.

[86] H. Moulinec, P. Suquet, A numerical method for computing the overall responnse of nonlinear composites with complex microstructure, Computer Methods in Applied Mechanics and Engineering 157 (1998) 69-94.

[87] T. Helfer, B. Michel, J.-M. Proix, M. Salvo, J. Sercombe, M. Casella, Introducing the open-source mfront code generator: Application to mechanical behaviours and material knowledge management within the pleiades fuel element modelling platform, Computers \& Mathematics with Applications 70 (2015) 994-1023. 